\title{
COLORADOSCHOOLOFMINES
}

EARTH•ENERGY•ENVIRONMENT

Division of ECONOMICS AND Business
WORKING PAPER SERIES

\section{A Look Upstream: Electricity Market Restructuring, Risk, Procurement Contracts and Efficiency}

Corrado Di Maria

Ian Lange

Emiliya Lazarova

\author{
Working Paper 2014-12 \\ http: //econbus.mines . edu/working-papers/wp201412.pdf \\ Colorado School of Mines \\ Division of Economics and Business \\ 1500 Illinois Street \\ Golden, CO 80401
}

November 2014

(c) 2014 by the listed authors. All rights reserved. 
Colorado School of Mines

Division of Economics and Business

Working Paper No. 2014-12

November 2014

Title:

A Look Upstream: Electricity Market Restructuring, Risk, Procurement Contracts and Efficiency*

Author(s):

Corrado Di Maria

School of Economics

University of East Anglia

Norwich Reasearch Park

Norwich NR4 7TJ

United Kingdom

c.di-maria@uea.ac.uk

Ian Lange

Division of Economics and Business

Colorado School of Mines

Golden, CO 80401-1887

ilange@mines .edu

Emiliya Lazarova

School of Economics

University of East Anglia

e.lazarova@uea.ac.uk

\begin{abstract}
This paper analyzes theoretically and empirically how upstream markets are affected by deregulation downstream. Deregulation tends to increase the level of uncertainty in the upstream market. Our theoretical analysis predicts that deregulated firms respond to this increase in uncertainty by writing more rigid contracts with their suppliers. Using the restructuring of the electricity market in the U.S. as our case study, we find support for our theoretical predictions. Furthermore, we investigate the impact this change in procurement contracts has on efficiency. Focusing on coal mines, we find that those selling coal to plants in restructured markets are significantly more productive than their counterparts working with regulated plants. On the other hand, we also find that transaction costs may have increased as a consequence of deregulation.
\end{abstract}

\title{
JEL classifications: L14, L15, Q31, Q48
}

Keywords: Energy Policy, Electricity Market Restructuring, Deregulation, Procurement Contracts, Risk, Efficiency.

\footnotetext{
${ }^{*}$ We would like to thank Harrison Fell, Ashley Langer, Derek Lemoine, Pete Maniloff, Mirko Moro, and Chris Timmins for their comments and suggestions. We gratefully acknowledge helpful discussions at WCERE 2014 in Istanbul, SURED 2014 in Ascona, and the 2014 CU Workshop of Environmental and Resource Economics in Vail, as well as the many comments received during seminars at the University of Manchester, the Graduate Institute in Geneva, the University of East Anglia, the University of Central Florida, and the University of Basel.
} 


\section{Introduction}

Firms operating in regulated markets, especially those working under cost-of-service regulation, are often thought to be less efficient than firms operating under conditions of competition. Competitive markets are in fact commonly viewed by economists as conducive to higher technical efficiency. In most cases the argument relies on the notion that, in more competitive environments, firms face stronger incentives for cost-minimization on the part of effort-averse managers than would instead be the case in a regulated context (Laffont and Tirole, 1993). Moving from this intellectual premise, many economists advocate freer, more competitive markets as the means to improve efficiency, reduce prices and increase welfare.

In one of the rare occasions in which policy-makers have eagerly applied the prescriptions of economists, policy measures aimed at fostering competition have been commonplace in OECD countries since at least the late 1970s. Especially frequent have been attempts to deregulate previously regulated natural monopolies such as telecommunications, rail and air transportation, water provision, and energy generation and distribution. Naturally, economists interested in assessing the effects of competition have not missed the opportunity to evaluate such policy changes (Olley and Pakes, 1996; Ng and Seabright, 2001; Syverson, 2004; Davis and Kilian, 2011, among others).

In this context, the restructuring of electricity markets has received special attention, due to a combination of political salience and data availability (e.g. Newbery and Pollitt, 1997; Wolfram, 1999; Borenstein, Bushnell, and Wolak, 2002; Malik, Cropper, Limonov, and Singh, 2011). Most contributions assessing the impact of deregulation in the electricity industry, however, have to date taken a rather narrow view of the issues and discussed the consequences of the policy exclusively from the point of view of firms operating directly in the deregulated market (Borenstein et al., 2002; Bushnell and Wolfram, 2005; Fabrizio, Rose, and Wolfram, 2007; Zhang, 2007; Davis and Wolfram, 2012). Such analyses, while informative, provide at best a partial picture of the overall consequences of deregulation. Abstracting from the impacts of restructuring on the supply chain upstream from the deregulated market is a relevant omission from a theoretical standpoint as the aim of the policy is to increase welfare by eliminating all types of inefficiencies and transferring the associated rents to the final consumers. This omission is also likely to be empirically relevant in all those situations where the cost of specific inputs represents a significant share of the total costs of production, as is true of fuel costs in coal-fired electricity generation, which contribute over $80 \%$ to total variable costs (Cicala, 2014).

In this paper, we take a first step into investigating the consequences of regulation upwards along the supply chain. To do this, we develop a theoretical model to analyze how deregulation efforts impact the contracting process between electricity generators and coal mines. In our efforts we are guided by the literature on procurement contracts in coal-fired electricity generation mostly associated with the name of Paul Joskow. This literature identifies the key dimensions along which long-term contracts are negotiated in the price adjustment mechanism and the length of the contract (e.g., Joskow, 1985, 1987, 1988). Accordingly, we model the choice of contracts in terms of the rigidity of the price setting mechanism and the contractual duration. Our analysis focuses on the changes in the degree of uncertainty in the operating environment for energy generators which ensue from the shift from cost-of-service regulation to market competition. While previous work has noted that "firms that do not have the security of a guaranteed rate of return on their investments will be more prudent in [...] the 
way they manage risk" (Borenstein and Bushnell, 2000), no work to date has investigated the impact of this increased uncertainty on procurement strategies. The key conclusions we derive from our theoretical model are that one would expect to observe more rigid (e.g., fixed-price), shorter contracts in restructured markets, as a consequence of risk-sharing attempts. The second step in our analysis is to take these theoretical predictions to the data. The peculiar history of deregulation in the United States presents us with the unique opportunity to identify a suitable control group for the plants exogenously 'treated' with restructuring. ${ }^{1}$. This enables us to identify the causal effects of restructuring on the deregulated plants. Using data on actual contracts signed by U.S. coal-fired generators with coal mines over the period 1990-2001, we find that the data substantially support our theoretical insights. In the final part of our work, we discuss the implications of our results for the overall efficiency of the industry. On the one hand, contracts with more rigid price setting de facto make the coal mine the residual claimant to any efficiency gain, and provide higher-powered incentives for cost reductions. In this case, we would expect to observe increases in productivity in mines that sell coal to deregulated plants, for example. Using data on labor productivity in the mining industry, we conclude that more rigid pricing mechanisms in contracts are indeed associated with productivity gains. On the other hand, we also note that shorter and more rigid contracts imply higher transaction costs per unit of time, which in itself reduces the overall level of efficiency. Our final empirical effort confirms that the changes in contracting practices we identify can be linked to more frequent renegotiations, and to an ensuing increase in transaction costs.

Our focus in this paper is on understanding how the contracting behaviour of electricity generators adapts as the regulatory framework for the industry changes. We are particularly interested in studying the impact of the increased exposure to risk experienced by electricity generators once cost-of-service regulation is removed, and they find themselves operating in a competitive market. In this new environment, far from being guaranteed the recovery of (prudently incurred) costs and an appropriate rate of return as under cost-of-service regulation, electricity generators are faced with volatile fuel prices and unpredictable (wholesale) electricity prices. Thus, the attitudes to risk of both electricity generators and coal mines matter. While a significant part of the literature seems to indicate that the empirical evidence supports a risk neutrality assumption for contracting parties (e.g. Allen and Lueck, 1995), Ackerberg and Botticini (2002) show that, once the endogenous nature of the match between the seller and the buyer is accounted for, the empirical evidence supports the hypothesis that different attitudes towards risk play a significant role in contract choices. This is likely to be especially the case in an industry, such as coal-fired electricity generation, where the opportunity costs for failing to produce are large ${ }^{2}$ and the transportation and storage costs for their bulky input are substantial, with the consequent inflexibility of operation in the short-run. It seems plausible, therefore, that producers operating in such an environment would be concerned

\footnotetext{
${ }^{1}$ As will be discussed in further detail below, restructuring was exogenous to coal contracting as states restructured due to lack of relatively cheap hydroelectric generation opportunities and/or sunk, irreversible generation investments from the 1970s and 80s (Borenstein and Bushnell, 2000)

${ }^{2}$ It is generally understood that the state and electricity utilities had a "regulatory compact" where consumers accepted a monopolist provider and the utility accepted an obligation to produce (McDermott, 2012).
} 
not only with the expected returns of their decisions, but also with the associated risks. ${ }^{3,4}$ With this in mind, we adopt the classical Markowitz $(1952,1991)$ framework, and model the choice of contract similarly to a problem of portfolio selection. In our case the value of a contract can be expressed as a function of its expected returns (i.e. the profits associated with it), and its riskiness. Rather than resorting to traditional proxies for risk such as the variance, however, we build on current practice in the financial literature and use the concept of Conditional Value at Risk to capture the risk associated with a contract (Rockafellar and Uryasev, 2000; Yamai and Yoshiba, 2005).

Our work is in the spirit of the seminal contribution by Cheung (1969), as we explicitly study the trade-off between transaction costs and risk distribution between contracting parties associated with different contractual arrangements, and it is also related to the vast literature on procurement contracts. ${ }^{5}$ Among the many theoretical contributions on optimal procurement contracts and asymmetric information, our paper is closest to those that study moral hazard in procurement. McAfee and McMillan (1986) is a classic reference in this respect. There the optimal contract offered by the buyer to the risk averse seller implements a partial reimbursement rule that trades off incentives for cost reduction effort and the need to share risk. Similarly, Bajari and Tadelis (2001) focus on the trade-off between the cost reduction incentives and ex-post renegotiation inefficiencies. Like these authors, we adopt a transaction cost approach to model the exposure to risk. In our framework the optimal contract balances the cost on contracting against the exposure to upstream uncertainty/risk (from the fuel price), by determining the optimal degree of price rigidity specified in the contract.

Due to data limitations, the empirical contract literature has lagged somewhat behind its theoretical counterpart. ${ }^{6}$ Nevertheless, several authors have investigated the determinants of contract choice using different proxies for the characteristics of the principal, the agent and the task being contracted. Allen and Lueck (1992), Laffont and Matoussi (1995), and Ackerberg and Botticini (2002) focus on the determinants of agrarian contracts, Leffler and Rucker (1991) look at timber harvesting, while Martin (1988), Lafontaine (1991), and Slade (1996) discuss contract choice in business franchising. Closer to our work, Corts and Singh (2004) study the impact of repeated interaction on the choice of fixed-price versus cost-plus contracts in the offshore drilling industry, while Joskow (1987), Kerkvliet and Shogren (2001) and Kozhevnikova and Lange (2009) look specifically at the determinants of contractual

\footnotetext{
${ }^{3}$ In moving away from risk-neutrality, we follow a number of very influential contributions dealing with firms operating under price uncertainty. Seminal contributions in this context are Baron (1970); Sandmo (1971); Holthausen (1979).

${ }^{4}$ In principle, a variety of financial instruments - forward contracts, futures contracts, options, etc. - are available to generators to hedge those risks. In practice, however, given the limited possibility to efficiently store electricity, the severe constraints that exist on its transmission (both in physical terms and in terms of reliability), and the inelastic nature of (short-run) electricity demand, electricity prices on deregulated wholesale markets are substantially more volatile than any other commodity price (e.g. Liu, $\mathrm{Wu}$, and $\mathrm{Ni}$, 2006; Yu, Somani, and Tesfatsion, 2010), thus making effective hedging much more difficult. As refers to input prices, Gross, Blyrth, and Heptonstall (2010) discuss the difficulty of hedging against long-run fuel price uncertainty. As a result, electricity generators need to accept the impossibility of perfectly hedging against the types of risk mentioned above. In this sense, our analysis can be seen as a study of how the residual risk (after hedging) coming from both the downstream wholesale electricity price volatility, and upstream fuel price uncertainty shapes the optimal contractual arrangements on the upstream market.

${ }^{5}$ Che (2008) provides an excellent overview of the standard economic models of optimal procurement in markets with limited information. The literature review in Asker and Cantillon (2010) provides a more comprehensive list of publications in this literature.

${ }^{6}$ For two recent surveys of this literature see Chiappori and Salanié (2002), and Corts and Singh (2004).
} 
duration in coal procurement using U.S. data. In the present paper, we study the interaction between the price rigidity decision and the length of the contract, explicitly modelling the two decisions as simultaneously chosen characteristics of the optimal contract.

The rest of the paper proceeds as follows, section 2 provides a concise overview of the market for coal in the U.S. in the period covered by our analysis and discusses the restructuring process started in the early 1990s. Section 3 contains our theoretical discussion and concludes with the testable implications that we take to the data. Section 4 presents the empirical strategy, describes the data and discusses the results. In section 5 we discuss the implications of our theoretical and empirical analysis in terms of mine productivity and contract renegotiation. Finally, section 6 concludes.

\section{An overview of procurement choices in the coal-fired gen- eration industry in the U.S.}

Our analysis focuses on the period between 1990 and 2001. This period corresponds to the peak of coal usage in the U.S. electricity market, as the oil embargoes of the 1970s created the conditions for an expansion in coal-fired electricity generation capacity. Coal supplied around $50 \%$ of the U.S. electricity through the 1980s, 1990s, and the early 2000s (U.S. EIA, 2010). Since coal plants tend to have higher start-up and shut-down costs, relative to oil and gas plants, coal capacity was generally built to supply the base-load of the electricity system, meaning that it was expected to run at all hours of the day, whereas oil and gas would only run for shorter periods. Hence, the main operational concern for operators of coal-fired boilers was to ensure an adequate and consistent supply of coal to meet base-load electricity demand. This led plants to utilize complex long-term forward contracts for fuel procurement. Different types of contracts were developed, with varying degree of price rigidity. At one end of the spectrum one finds 'fixed-price' contracts, which would specify a single delivery price for the entire duration of the contract; at the other end of the spectrum, instead, the so-called 'evergreen' contracts stipulated that the price would be renegotiated at predetermined intervals, usually once a year. Other contracts had intermediate degrees of price rigidity, such as contracts that would specify a base price and a formula to compute increases or decreases from this base price, depending on economic and market conditions ('base-price plus escalation' contracts). ${ }^{7}$

These contracts proved to be surprisingly resilient to changes in input market regulation such as railroad market restructuring, and the emergence of a large spot market in the Western coal producing states (Joskow, 1985, 1990).

The desire for quantity/quality certainty, and the associated use of long-term forward contracts, was re-enforced by the structure of economic regulation in the electricity sector. Plants were regulated under a cost-of-service regulation, where the price of electricity was guaranteed by the state, depending on the plant's cost of generation. Crucially, once the state public utility commissions (PUCs) approved a coal contract, they would then allow the plant to be compensated for the prices paid under that contract. The regulator put large weight on ensuring supply would meet demand, rather than focusing on the cost of electricity.

\footnotetext{
${ }^{7}$ Table 1 summarizes the most common types of contracts and the definition provided by the Federal Energy Regulatory Commission (FERC) to plants in the survey's documentation
} 
Moreover, most plants were part of an integrated utility that also managed the transmission and distribution grids, so they had a great deal of certainty with respect to both the price and quantity of the electricity they would sell. In this situation, it was very difficult for new entrants to gain access to the market, given that the incumbents managed the grid. This state of affairs considerably reduced the generators' incentives to minimize their generation costs, and left the mines with little pressure to improve their efficiency.

In 1992, the federal Energy Policy Act mandated that non-discriminatory access to the transmission grid be guaranteed, in an effort to encourage new generators to enter the market. Many states were also interested in encouraging lower cost generators to enter the generation market, and thus held hearings on how to reform their regulation of the electricity market. These hearings addressed possible ways to bring competition to the generation of electricity through potential legislation that separated transmission and distribution services from the generation and retail services of the electricity market. States that went through with electricity market restructuring set up a market where plants generally had to bid for the right to put electricity onto the transmission system and thus sell their output. Table 2 gives a list of the years when hearings were held and restructuring legislation passed, by state. Compared to the economic regulation that had existed before the mid-1990s, restructured electricity markets introduced risk in the output market for electricity generators. Whereas electricity generators in regulated markets were only marginally concerned by price uncertainty, in restructured markets little guarantee existed as to either price or quantity. In the next section we present a theoretical model to analyze how this change in uncertainty might have affected the choice of contract in the negotiation between electricity generators and coal mines.

\section{A model of fuel procurement in electricity generation}

Our goal is to model the interaction between a coal-fired electricity generator and a coal mine, with the specific goal of understanding how changes in the regulatory environment downstream, i.e. on the wholesale electricity market, might affect the behaviour of the parties. ${ }^{8}$ The electricity producer needs to source coal to produce steam to generate electricity for sale on the downstream market. The mine, on the other hand, extracts coal from the ground and sells it. ${ }^{9}$ This interaction may result in the parties writing long-term procurement contracts for the delivery of coal from the mine to the generator (e.g. Joskow, 1985).

\subsection{The value of a contract}

While coal contracts can be very complex, for our purposes here it suffices to focus on two elements of the procurement contract, namely the price paid for each unit of coal, $p^{c}$, and the duration, $d$, of the contract itself. We simplify our analysis by assuming that the quantity of coal contracted for delivery is given and can be normalized to one. ${ }^{10}$ Furthermore, building

\footnotetext{
${ }^{8}$ In what follows we use the terms 'producer', 'generator', 'buyer' or simply 'plant' interchangeably. Instead, we refer to the coal producer as the 'mine', or simply the 'seller'.

${ }^{9}$ Between 1990 and 2001, on average 92\% of all coal mined in the United States was used to generate electricity. Thus, neglecting alternative uses of mined coal is unlikely to be a significant omission in this context.

${ }^{10}$ Most coal-fired generators served as base-load generation during our sample given their low marginal cost of generation, and their high cost of ramping production up or down. Hence, such generators produce
} 
on the insights provided by Crio and Condren (1984) and Kerkvliet and Shogren (1992), we treat all aspects of the contract that refers to the quality of coal as exogenous. ${ }^{11}$

As regards the price of coal, the contract needs to specify how it is to be determined over the whole duration of the contract. Different price adjustment provisions may be included in procurement contracts (see e.g., Joskow, 1988). The price can be fixed for the whole duration of the contract, which leads to the aptly named fixed-price contract, for example. It can, however, be allowed to change over time, for example to compensate - partially or totally the mine for unexpected changes in the level of its costs, or to reflect changes in economic conditions. To capture the varying degree to which the price of coal is linked to the mining costs, we can write the delivery price of coal as the sum of a component that allows the seller to recoup its operating costs, $(1-r) x(\chi, e)$, and a fixed part that allows for an appropriate rate of return on its assets, $\delta(r)$. In this way the degree of rigidity of the pricing mechanism is completely captured by the value of $r$ :

$$
p^{c}=(1-r) x(\chi, e)+\delta(r)
$$

In the expression above $x(\chi, e)$ represents the production costs incurred by the mine. ${ }^{12}$ These costs are uncertain and depend on the physical properties of the coal seam, as well as other characteristics such as the degree of unionization of the labour force. To capture the idea that these costs vary across locations, we assume that mining costs depend positively on a random variable, $\chi$, whose probability distribution is known to the mine, but whose actual realization is not known at the time the contract is written. The mine may, however, affect the level of its mining costs by exerting effort, $e \geq 0$, for example in order to increase its productivity. Effort is costly, and the cost of effort, $g(e)$, is increasing and convex, i.e. $g(0)=0$, with $g^{\prime}>0$, and $g^{\prime \prime} \geq 0$. We also assume that these private costs are unobservable by the generator. ${ }^{13}$

For the sake of analytical tractability it turns out to be convenient to assume that $x(\chi, e)$ is normally distributed with mean $\mathbb{E}(x)$ and variance $\sigma_{x}^{2}$. In line with the moral hazard literature, we assume that effort may reduce the expected level of costs, but becomes gradually less effective. Formally, we let $\partial \mathbb{E}(x) / \partial e<0$ and $\partial^{2} \mathbb{E}(x) / \partial e^{2} \geq 0$. At least in principle, however, effort might also affect the variance of the mining costs. One could imagine, for example, that cost-reducing efforts could be aimed at reducing administrative costs with little effect on actual production activities. In this case cost-reducing effort would not affect the variance of costs, and $\partial \sigma_{x}^{2} / \partial e=0$. This is equivalent to saying that, for any effort levels $e<e^{\prime}, x(\chi, e)$ first order stochastically dominates $x\left(\chi, e^{\prime}\right)$. On the other hand, as we will further elaborate in the next section, both the mine and the generator value certainty. Thus, cost-reducing effort could be directly aimed at reducing the variance of production costs. This could be achieved, for example, by prioritizing the development of shallower

continuously and their main concern in terms of procurement is the availability of a sufficient quantity of coal. In this market segment, then, the quantity of coal to be delivered each period is very closely related to the productive capacity of the electricity generator, and can be considered constant.

${ }^{11}$ Crio and Condren (1984) and Kerkvliet and Shogren (1992) remark that long term contracts specify the physical attributes of the coal in order to match the design specifications of the boilers. Hence, the physical attributes specified in the contract (usually the heat, sulfur, ash, and moisture content) are a function of the technical characteristics of the boiler, and as such are exogenous to the choice of contract.

${ }^{12}$ The mine's main activity is to extract coal from the ground. This is a complex process, which typically entails drilling and blasting the coal seam, removing the coal, crushing and separating the coal from other by-products, stockpiling and shipping.

${ }^{13}$ Notice that in this context contracting on the degree of price rigidity is equivalent to contracting on effort, given the monotonic relationship between effort and rigidity. This is formally shown in Lemma 1 below. 
seams or continuous production scheduling. In such cases, we would expect that $\partial \sigma_{x}^{2} / \partial e<0$. Finally, as recently shown by Buessing and Weil (2014), certain types of efforts targeted at reducing the level of costs in mining could have as unintended consequence an increase in the probability of injuries or fatalities. This would imply an increase in the variance of extraction costs. Hence, it is also plausible that $\partial \sigma_{x}^{2} / \partial e>0$. Our framework nests all these three alternative scenarios.

As discussed in Section 2, several types of contracts have long coexisted in this industry. To allow for this possibility in our theoretical model, we need to impose that the level of the price of coal be the same, ex-ante, across contracts. In order for this to happen, we need to adjust the level of the fixed component such that the expected price remains the same, irrespective of the degree of contractual price rigidity. It follows that $\delta$ becomes an increasing function of $r$. To see this, consider first a fixed price contract where no cost recovery is allowed. In this case $r=1$ and $p^{c}=\delta(1)=\bar{\delta}$. For the ex-ante price of coal to be the same across contracts with different degrees of price rigidity, it must hold that $\mathbb{E}\left(p^{c}\right)=\delta(r)+(1-r) \mathbb{E}(x)=\bar{\delta}$, or, equivalently, that:

$$
\delta(r)=\bar{\delta}-(1-r) \mathbb{E}(x) .
$$

In line with the theoretical underpinnings of the transaction cost approach to contracting (Coase, 1937; Cheung, 1969; Williamson, 1985), we assume that for both sellers and buyers negotiating an agreement, writing the relative contract, and managing the ensuing relationship with the counterpart entails potentially large costs, including the opportunity cost of devoting resources to contracting and administering the contract, rather than to alternative, more productive activities. We also assume, as discussed at length below, that different types of contracts entail different transaction costs, depending on the contract rigidity, and its duration. Quite naturally, we assume that more complex relationships - in particular those that require higher level of relation-specific assets - are generally more costly to shape and maintain (Joskow, 1987). Crucially, we assume that these costs cannot be practically attributed to specific accounting posts and that, as a consequence, they cannot be included in the costs that can be recovered under a cost-plus contract by the seller, and under cost-of-service regulation by the buyer. In other words, transaction costs always contribute negatively to profits, irrespective of the regulatory environment and the pricing mechanism.

Given (1), we can parameterize the price setting mechanism by $r$, and define a 'contract' as a pair, $\boldsymbol{\gamma}=(r, d)$. From the set of all possible contracts, $\Gamma$, the parties will select the contract $\gamma$ that maximizes the benefits they derive from the contractual relationship. Similarly to the familiar Markowitz (1952) set-up, we assume that both types of agents value contracts according to their perceived trade-off between risk and expected return. In line with recent practice in the financial contracting literature, however, rather than measuring risk using the variance of the portfolio returns, we adopt the concept of conditional-value-at-risk $\left(C V a R_{\alpha}\right)$ as our proxy for risk (Rockafellar and Uryasev, 2000). ${ }^{14}$ As a consequence, both types of

\footnotetext{
${ }^{14}$ For any given confidence level $\alpha$, the value-at-risk, or $V a R_{\alpha}$, of a portfolio is given by the smallest number $v$ such that the probability that the loss in portfolio value exceeds $v$ is not greater than $(1-\alpha)$. The $C V a R_{\alpha}$ of a portfolio is, instead, defined as the expected loss in portfolio value during a specified period, conditional on the event that the loss is greater than or equal to $V a R_{\alpha}$. Thus, $C V a R_{\alpha}$ informs a portfolio holder about the size of the expected loss, conditional on the occurrence of an unfavorable event, rather than simply indicating the probability of an unfavorable event (Rockafellar and Uryasev, 2000). A rich literature exists, which discusses the relative merits of $C V a R_{\alpha}$ and $V a R_{\alpha}$. For a comprehensive discussion, the reader is referred to Yamai and Yoshiba (2005). For examples of papers using $C V a R_{\alpha}$ in the context of electricity markets, see Liu et al. (2006) and Yu et al. (2010).
} 
firm choose the contract that provides the best combination of expected profits and the size of the potential adverse consequences associated with the contract. The per-period value of contract $\boldsymbol{\gamma}=(r, d)$ to firm type $i=\{g, m\}$, can thus be written in general terms as follows:

$$
V^{i}(\gamma)=\mathbb{E}\left(\pi^{i}\right)-\theta^{i} C V a R_{\alpha}\left(-\pi^{i}\right), \text { for } i=\{g, m\},
$$

where $g$ and $m$ are the generator's and the mine's identifiers, respectively, and $\theta^{i}$ is the relative weight attached to risk by type $i$ in its objective function.

\subsection{The mine}

We start by specializing (3) for the case of the coal mine. Having extracted and processed the coal, the mine delivers it to the generator in exchange for the agreed price, $p^{c}$. Taking into account that the mine incurs production costs, $x(\chi, e)$, effort costs, $g(e)$, and - as discussed above - transaction costs, $k^{m}$, we can write the mine's profits as

$$
\pi^{m}=p^{c}-x(\chi, e)-g(e)-k^{m}(r, d ; \mathbf{A}) .
$$

Our assumptions regarding the transaction cost component $k^{m}$, which are derived from the literature and from our understanding of the industry, warrant some discussion. First of all, building on the large existing literature on contract completeness, it is quite natural to think that the transaction costs $k^{m}$ would change with the pricing mechanism, and the duration of contract being stipulated (e.g. Tadelis and Williamson, 2012). On the one hand, a more rigid contract may be more costly to negotiate, as there are simply more contingencies to contemplate (Bajari and Tadelis, 2001); on the other hand, a contract that specifies the price more rigidly - such as a fixed-price contract - would reduce the level of effort exerted by the mine in accounting for, documenting and reporting its operating costs. As such, it entails lower administrative costs for the seller (Joskow, 1985). In what follows, we assume that the latter effect is particularly important from the point of view of the mine, and thus assume that $k^{m}$ is decreasing with $r$, i.e. we let $\partial k^{m} / \partial r<0$. As refers to the duration stipulated in the contract, instead, one would normally believe that a longer contract would allow for the fixed stipulation costs to be spread over a longer time period, and hence reduce the per-period administrative costs. One needs to consider, however, that the longer the contract duration specified in the contract, the higher the probability that the seller might find it advantageous to breach the existing contract. This tendency might be driven by the desire to pursue more lucrative alternative opportunities elsewhere - a situation discussed, for example, by Joskow (1988) - or might arise because of negative developments in productive conditions. As discussed in section 2 above, coal procurement contracts specify in great detail the characteristics of the coal to be delivered, for example its heat, ash, moisture and sulfur contents. If the productive conditions of the mine change - because of an unexpected deterioration in the quality of the coal they extract, for example - the mine might find it very costly to keep operating within the framework of its current contractual obligations, and might prefer to breach the contract. Either way, breaching the contract adds more transaction costs and potentially large litigation costs to the total. With all this in mind, we conclude that $k^{m}$ is likely to be increasing with contractual duration, $d$, i.e. $\partial k^{m} / \partial d>0$. In what follows we also assume that transaction costs are strictly convex in both arguments, so that $\partial^{2} k^{m} / \partial x^{2}>0$, for $x \in\{r, d\}$. Since the likelihood of breach of contract is particularly high for contracts with 
more rigid price setting mechanisms, we further assume that $\partial^{2} k^{m} /(\partial r \partial d)>0 .{ }^{15}$ Finally, the type of transaction costs discussed above may be affected by other factors, among which relation-specific investments feature prominently, as discussed by Joskow (1987). To reflect this possibility, we write the transaction cost component as $k^{m}(r, d ; \mathbf{A})$, where $\mathbf{A}$ is a vector of cost-shifters. The need to incur relation-specific investments tends to increase the cost of entering the contractual relationship; at the same time, the presence of relation-specific assets is likely to reduce the attractiveness of alternative opportunities. Both arguments imply that a longer contractual duration becomes more desirable as the sunk costs may be spread over more periods, and the likelihood of breaching the contract is reduced. ${ }^{16}$ This reasoning leads us to conclude that the marginal costs of a longer contractual duration decrease with $\mathbf{A}$, i.e. $\partial^{2} k^{m} /\left(\partial d \partial A_{i}\right)<0$ for each component $A_{i}$ of $\mathbf{A} .^{17}$

Substituting (1) into (4), and given our assumption that mining costs are distributed according to $N\left(\mathbb{E}(x), \sigma_{x}^{2}\right)$, we can express the value to the mine of entering into contract $\gamma$ with the buyer as follows:

$$
V^{m}(\boldsymbol{\gamma}, e)=\left(1+\theta^{m}\right)\left[\bar{\delta}-\mathbb{E}(x(\chi, e))-k^{m}(r, d ; \mathbf{A})-g(e)\right]-\theta^{m} b(\alpha) r \sigma_{x},
$$

where we made use of the fact that, as shown by Rockafellar and Uryasev (2000), for normally distributed portfolios the conditional value at risk can be written as

$$
C V a R_{\alpha}(-\pi)=-\mathbb{E}(\pi)+b(\alpha) \sqrt{\operatorname{Var}(\pi)},
$$

where

$$
b(\alpha)=\left(\sqrt{2 \pi} \exp \left(\operatorname{erf}^{-1}(2 \alpha-1)\right)^{2}(1-\alpha)\right)^{-1},
$$

and $\operatorname{erf}(z)=(2 / \sqrt{\pi}) \int_{o}^{z} \exp \left(-s^{2}\right) \mathrm{d} s$ is the Gauss error function.

From (5) it follows that for any given contract $\gamma=(r, d)$ the mine would optimally choose its level of effort, to maximise its benefits from the contract. It turns out, however, that the decisions on the optimal degree price rigidity and on the optimal level of effort are intimately related. In fact, we can show that it is possible to fully characterize the optimal choice of effort as a function of the degree of price rigidity only, as emerges from the statement below:

Lemma 1. Given equation (5) and any exogenous contact $\gamma=(r, d)$, the mine's optimal choice of effort, $e^{*}$, is a monotonic function of the level of rigidity $r$. Moreover, $e^{*}(r)$ is an increasing function, provided that

$$
\left(1+\theta^{m}\right) \frac{\partial \mathbb{E}(x)}{\partial e}+\theta^{m} b(\alpha) \frac{\partial \sigma_{x}}{\partial e}<0
$$

Proof. See Appendix A.

\footnotetext{
${ }^{15}$ In this respect, Joskow (1988) writes "While almost any price-adjustment provision could lead to large disparities between contract prices and "market prices" if certain contingencies arise, and thereby provide incentives for either the buyer or the seller to breach, a fixed-price contract almost guarantees that these problems will arise".

${ }^{16}$ Joskow (1985) concludes that "The empirical results [...] provided strong support for the hypothesis that buyers and sellers make longer ex ante commitments to the terms of future trade, and rely less on repeated negotiations over time, when relationship-specific investments are more important".

${ }^{17}$ Since we have no priors about the impact of changes in relation-specific investments on the degree of rigidity of the pricing mechanism, nor could we think of a mechanism through which a change in $A$ would directly affect the cost of $r$, in what follows we assume $\partial^{2} k^{m} /(\partial r \partial A)=0$.
} 
The implications of this results are clear, as long as effort is "worth it" 18 , contracts with less flexible price provisions introduce higher powered incentives for cost-reduction by making the mine the residual claimant of any efficiency gain.

It directly follows from Lemma 1 that in the remainder of the paper, it will suffice to concentrate on the choice of contractual rigidity, while the optimal level of effort will be a direct consequence of the choice of $r$. Accordingly, with a slight abuse of notation, from now on we let $V^{m}(\gamma) \equiv V^{m}\left(\gamma, e^{*}(\gamma)\right)$.

\subsection{The electricity generator}

To derive the expression that represents the value of the contract from the point of view of the electricity producer, we first need to consider the determinants of the generator's profits. Obviously, the generator derives revenues from the sale of electricity, which may occur either on a regulated or a liberalized market. When the generator operates within a regulated market, the unit price of electricity $\left(p^{e}\right)$ is set by the regulator to cover the firm's operating costs $(c)$ and allow for a fair rate of return on its assets. In this case, we can write $p^{e}=\mu+c$, where $\mu$ represents the unitary mark-up over costs recognized by the regulator. ${ }^{19}$ When the generator sells electricity on a liberalized market, it instead faces a competitive environment, and takes the price of electricity as exogenously given. Since the price of electricity is ex-ante unknown, this introduces uncertainty in the generator's objective function. For the sake of simplicity, we assume that $p^{e}$ is normally distributed with mean $\mathbb{E}\left(p^{e}\right)$, and standard deviation $\sigma_{e}$.

To generate electricity, the producer naturally incurs costs. In this simplified set-up, we focus purely on fuel costs and abstract from all remaining operating costs. This assumption allows us to transparently bring to the fore the role of input-cost risk, as in this context $c$ simply equals $p^{c}$, the price of one unit of coal. ${ }^{20}$

As in the case of the coal mine, in addition to these operating costs, we include in the profit expression the transaction costs, $k^{g}$, associated with bargaining, contracting, and managing the relationship with the counterpart. We assume that $k^{g}$ is increasing with the degree of price rigidity as writing a more rigid contract is more costly and, contrary to the seller, the generator doesn't save on administrative costs by being in a more rigid contract. Thus, we have $\partial k^{g} / \partial r>0$. Furthermore, we assume that from the point of view of the generator the cost of contracting declines with the duration of the contract. Trivially in this case the costs

\footnotetext{
${ }^{18}$ The condition presented in Lemma 1 is readily interpreted as an "effectiveness condition" on effort. Given that from the point of view of the mine both a higher expected level and a higher variance of the costs represent negative attributes, the requirement that the marginal effect of effort on the weighted sum of the expected cost level and variance be negative is in effect just saying that effort should be effective in reducing the negative impact of $x$ (and $\sigma_{x}^{2}$ ) on the maximand in (5). Naturally, the weighting depends both on the mine's preference parameter for risk avoidance, $\theta$, and on the level of its risk tolerance $\alpha$.

${ }^{19}$ Note that to simplify the notation, we have chosen our measurement units such that one unit of electricity is produced with one unit of coal.

${ }^{20}$ Elsewhere in the literature, the role of capital investments features prominently. Most recently, Fowlie (2010) discusses the possibility that firms' choices of compliance options in the $\mathrm{NO}_{x}$ Budget Program were driven by the difference in capital cost recovery possibilities between restructured and regulated electricity markets. In the context of the present paper, however, capital investment is not a crucial determinant of the contractual behaviour of generators vis à vis coal mines. As a consequence, we abstract from this aspect in our theoretical discussion. We return to this topic when we discuss the empirical results in the second part of the paper.
} 
are incurred less frequently so the per-period cost decreases, and the generator does not face the costs discussed above for the mine, that arise from the expected breach of contract, so that $\partial k^{g} / \partial d<0 .{ }^{21}$ As discussed in the previous section, however, we want to allow for the possibility that the transaction costs discussed here might depend on a set of cost shifters, A. In this case, an increase in $\mathbf{A}$ - for example an increase in transaction-specific assets - further reduces the marginal cost of a the contractual duration. Thus, $k^{g}(r, d ; \mathbf{A})$, and $\partial^{2} k^{g} /\left(\partial d \partial A_{i}\right)<0$, for each $A_{i} \in \mathbf{A} .^{22}$

If we let $\lambda=\{0,1\}$ be an indicator of the regulatory context, which assumes the value 1 in a restructured market and 0 otherwise, we can concisely write the expression for profits for the generator across regulatory regimes, as follows:

$$
\pi^{g}=\lambda p^{e}+(1-\lambda)\left(\mu+p^{c}\right)-p^{c}-k^{g}(r, d ; \mathbf{A}), \text { for } \lambda=\{0,1\} .
$$

This implies that, from the point of view of the generator, the value of signing up to contract $\gamma=(r, d)$ is:

$$
V^{g}(\gamma)=\left(1+\theta^{g}\right)\left\{\lambda\left[\mathbb{E}\left(p^{e}\right)-\bar{\delta}-\mu\right]+\mu-k^{g}(r, d ; \mathbf{A})\right\}-\theta^{g} b(\alpha) \lambda \sqrt{\sigma_{e}^{2}+(1-r)^{2} \sigma_{x}^{2}} .
$$

In the expression above, we have once again made use of the normality assumption for both $p^{e}$ and $x$ to write the conditional value at risk as a function of the expected value and the standard deviation of the profit expression only, according to equation (6).

\subsection{The optimal choice of contract}

We assume that there is a large number of potential sellers (mines) on the market relative to the number of buyers (generators), so that we let the buyer make a take it or leave it offer to the seller, offering a contract that guarantees the mine a value of zero. ${ }^{23}$ With this assumption in mind, the problem of the generator reduces to the problem of selecting from the menu of all contracts, $\Gamma$, the one that maximizes its objective function, (8), while guaranteeing the participation of the mine. Formally, the generator chooses the contract $\gamma^{*}=\left(r^{*}, d^{*}\right)$ that solves

$$
\left.\gamma^{*} \equiv \underset{\gamma \in \Gamma}{\arg \max }=\left\{V^{g}(\gamma) \mid V^{m}(\gamma)\right) \geq 0\right\}
$$

We are now in a position to derive our first result, which refers to the impact of deregulation in the downstream market on the characteristics of the optimal contract:

Proposition 1. The degree of price rigidity specified by the optimal contract, $r^{*}$, is monotonically non-decreasing in the degree of market liberalization, $\lambda$, while the optimal duration

\footnotetext{
${ }^{21}$ This is because the generator has lower incentives to breach the contract than the mine, and it most likely would be on the receiving end of any compensation in case of breach of contract by the mine.

${ }^{22}$ Notice that as in the case of the mine, we assume that changes in $\mathbf{A}$ do not affect the marginal transaction cost of a more rigid contract, i.e. $\partial^{2} k^{g} /\left(\partial d \partial A_{i}\right)=0$.

${ }^{23}$ This assumption is made here for the sake of simplicity, and while this implies that the generator is able to extract all the rents, this is without loss of generality in terms of the results of Proposition 1 and 2. In fact, any other non-cooperative bargaining procedure that reallocates rents differently would imply qualitatively similar results. To see that this is indeed the case, consider the other polar case that assigns the role of proposer of the TIOLI offer to the mine. While this implies reversing roles in problem (9), it does not change the sign of any of the derivatives in Appendix B and C. As a consequence, our monotone comparative statics results go through without amendments.
} 
of the contract, $d^{*}$, is monotonically non-increasing in $\lambda$.

Proof. See Appendix B

According to this result, as the downstream market gets deregulated the generator finds it more profitable to offer contracts characterized by an increasing degree of price rigidity and/or a shorter duration to its coal provider. The result accords with our intuition. In a regulated market, the cost-of-service regulation faced by the generator de facto insulates it from any adverse realization of the mining cost variable, $x(\chi, e)$. Hence, in this context the generator only needs to pick the right combination of price rigidity and duration to minimize its transaction costs while at the same time ensuring the continued participation of the mine in the exchange. As the market gets liberalized (i.e. when $\lambda=1$ ), however, the generator is left facing the prospect of potential losses via the uncertainty associated with the now variable market price for its output, and the oscillation in the cost of its input - see the last term in equation (8). Since the electricity market is perfectly competitive by assumption, the only option left to the generator to reduce its exposure to risk is to limit the uncertainty associated with the price of coal. To achieve this, the generator offers the mine a contract with a higher degree of price rigidity which limits the negative consequences in terms of profits of a bad realization of $\chi$. In doing so, however, it is the turn of the mine to become more exposed to the same bad outcome. To satisfy the mine's participation constraint, the buyer needs to offer a shorter contractual duration, which reduces the cost of contracting for the mine, and makes the new contract more palatable.

The previous discussion underlines the fundamental tension that emerges from the point of view of the buyer, following the restructuring of the downstream market. In a restructured market, the electricity generator wishes to reduce its exposure to risk, but is not willing to incur excessive transaction costs, and at the same time she needs to satisfy the participation constraint for the mine. Thus, it accords with our intuition that the optimal choice of procurement contract may change with the overall level of risk, and with the relative costliness of the two instruments, $r$ and $d$, in terms of transaction costs, as is shown in the following result:

Proposition 2. The sign of the derivative of the optimal choice of contract rigidity and duration with respect to changes in the values of key parameters are as follows:

\begin{tabular}{lrr}
\hline & \multicolumn{2}{c}{ Choice variable } \\
\cline { 2 - 3 } Parameter & $r^{*}$ & $d^{*}$ \\
\hline$A_{i}$ & $\leq 0$ & $\geq 0$ \\
$\sigma_{e}^{2}$ & $\leq 0$ & $\geq 0$ \\
$\sigma_{x}^{2}$ & $?$ & $\geq 0$ \\
\hline
\end{tabular}

Proof. See Appendix C

The first line of the table in Proposition 2 informs us that an increase in any of the transaction cost-shifters, $A_{i}$, reduces $r$ and increases $d$. Clearly, since more relation-specific assets reduce the transaction costs associated with a longer contract, longer, less rigid contracts will 
naturally emerge from situations where sunk costs of this type are more pervasive, e.g. for mine-mouth plants-mine relationships (See the discussion in Joskow, 1987, for example). The mechanism at work here is also interesting as it will help us in our identification efforts in the empirical part of the paper. Given our theoretical model, the lengthening of the contractual duration is directly caused by the change in the relation-specific assets. The change in the pricing mechanism, instead, only emerges indirectly, by virtue of the strict convexity of the transaction cost functions.

Next, we turn to the consequences of an increase in risk, proxied by the volatility of the price of electricity, and the variance of the extraction costs. Since the $C V a R$ component of $V^{g}$ is increasing in both $\sigma_{e}^{2}$ and $\sigma_{x}^{2}$, it is evident that operating in a more uncertain environment carries the risk of higher losses for the generator. We start from an increase in the volatility of the price of electricity, which is relatively more straightforward to analyze. Firstly, notice that the generator does not have any instrument to insulate herself from an increase in $\sigma_{e}^{2}$. An increase in $\sigma_{e}^{2}$, moreover, decreases, at the margin, the effectiveness of $r$ in reducing $C V a R$. Indeed, the impact on $C V a R$ of an increase in the rigidity of the price setting mechanism is smaller, the more volatile the electricity prices (see Appendix C). It follows that, from the point of view of the generator, an increase in $r$ is not attractive in this context, since the higher transaction costs associated with more rigid contracts are no longer compensated by a sufficient reduction in $C V a R$. The generator will therefore prefer less rigid contracts, compared to what is optimal in a low- $\sigma_{e}^{2}$ environment. Further, recall that value of the contract for the generator, $V^{g}$, is increasing with contract duration, $d$. Thus, ceteris paribus, a generator would also prefer longer contracts. Let us now consider this issue from the point of view of the mine. We know that $V^{m}$ is decreasing with $d$, and may also be decreasing with $r$. This implies that to satisfy the mine's participation constraint while offering more flexible contract, the buyer may also choose to offer a longer contract, provided that indeed $V^{m}$ is decreasing in $r$. In this case the mine would be indifferent between the "high-volatility" less rigid, but longer contract, and the "low-volatility" more rigid, shorter contracts.

An increase in the dispersion of the extraction costs, $\sigma_{x}^{2}$, has less a clear-cut effect on the characteristics of the optimal contract. On the one hand, from the point of view of the generator a higher level of $\sigma_{x}^{2}$ implies higher $C V a R$. Thus, the generator may want to shelter from the increase in riskiness upstream by offering a more rigid contract to the mine. This is clearly the case, when the mine attaches no weight to risk in its objective function, i.e. when $\theta^{m}=0$. Furthermore, if the value of the contract for the mine, $V^{m}$, is increasing in rigidity, $r$, the generator can satisfy the mine's participation constraint and offer a longer contract, which reduces her transaction costs. If, on the other hand, the mine attaches a positive value on risk in its objective function (i.e., $\theta^{m}>0$ ), the generator needs to accommodate the tightening of the mine's participation constraint in equation (9), as the value of the contract for the mine unequivocally falls with $\sigma_{x}$. In this case, the effect of an increase in $\sigma_{x}^{2}$ on the optimal level of rigidity is ambiguous as it depends on whether the contract value for the mine is increasing or decreasing in $r$. It is, however, clear that this will never result in a contract with shorter duration, as this would results in a further tightening of the mine's participation constraint.

Similar to the case discussed above for changes in relation-specific assets, it is important to note here that changes in the level of risk exposure affect directly the optimal level of $r$, whereas the choice of contractual duration is only indirectly affected. We return to this property of the model when we discuss the strategy for empirical identification below. 


\subsection{Taking the theory to the data.}

The theoretical discussion presented so far provides several insights into the contracting behaviour of generators and coal mines. The key results, as summarized in Proposition 1, immediately lead us to formulate the main testable hypotheses that we are going to subject to empirical scrutiny in the next part of this paper. As refers to the degree of price rigidity, we can state the following:

Hypothesis 1. The degree of rigidity of the price-setting mechanism specified in the contract should not be lower, ceteris paribus, for contracts signed by electricity generators operating in restructured markets than for generators operating in non-restructured ones.

Its counterpart in terms of contract duration is:

Hypothesis 2. The duration specified in the contract should not be longer, ceteris paribus, for contracts signed by utilities operating in restructured markets than for utilities operating in non-restructured ones.

Thus, we would expect the electricity market restructuring to lead to more rigid and shorter contracts. As we know from Lemma 1, however, under appropriate conditions, an increase in rigidity should lead to an increase in the optimal level of cost-reducing effort exerted by mines. This brings us to the following implication of our theoretical model:

Hypothesis 3. Following restructuring, mines that sell coal to plants in restructured states should become more efficient relative to mines that do not.

One final implication of our theoretical framework emerges once we focus again on the incentives for contract breach that emerge from adverse realization of the mining cost variable. In section 3.2 we argued that such incentives are particularly strong when contracts are more rigid. We could then expect that an increase in contractual rigidity would lead to an increase in the frequency of contract breaches and of renegotiations.

Hypothesis 4. The frequency of contract renegotiations should be increasing with the rigidity of the contractual pricing mechanism.

This latter implication has, as a corollary, that following restructuring we should observe an increase in transaction costs in then market for coal.

\section{An empirical investigation of contract choices}

In the rest of the paper, we confront the implications of our theoretical analysis spelled out above with data. The first step is obviously to assess the impact of electricity market restructuring on the optimal choice of procurement contracts. Three aspects of this empirical endeavour are worth noting here: Firstly, and crucially for our empirical endeavour, the variation over time and across U.S. states of restructuring of electricity markets gives us the possibility to cast our analysis as a quasi-experiment with plants operating in regulated states acting as the control group against which to assess the behaviour of plants operating in states that have undergone restructuring. In this context, we are able to causally attribute 
the differences in contracting behaviour between treated and control plants to restructuring. Secondly, the theoretical discussion above emphasizes that the optimal contract choice entails a simultaneous decision in terms of price rigidity and duration of the procurement contract, whereas the available data only captures the observed equilibrium outcomes of the contracting process between plants and mines. This obviously leads to concerns about the existence of endogeneity and the related biases in the coefficient estimates of our empirical model. In order to correct for such potential biases, an instrumental variable (IV) approach can be utilized, and instruments for both rigidity and duration need to be employed. Finally, according to our theoretical results, the choice of contractual rigidity and duration depends among other things - on the riskiness of the operating environment for the generators, i.e. on $\sigma_{e}^{2}$, and on the volatility of coal production costs, $\sigma_{x}^{2}$. Both of these variables are not directly observed in our data and can only be proxy-ed with error. In the spirit of Ackerberg and Botticini (2002), this state of affairs raises concerns about the possibility that, in the presence of endogenous matching between plants and mines, this measurement errors might results in residual correlation between the proxies and the error terms in our regressions, potentially leading to biases in the estimated coefficients. To control for this possibility, we can augment our empirical procedures with a matching equation à la Ackerberg and Botticini (2002). We return to the last two aspects in the next section, when we discuss identification issues in more detail.

In general terms, the model we will attempt to estimate in this section can be written as:

$$
\begin{aligned}
& r_{i}=\alpha_{0}+\alpha_{1} d_{i}+\alpha_{2} \Delta_{i}+\alpha_{3} \mathbf{X}_{\mathbf{i}}+\alpha_{4} \mathbf{Z}_{\mathbf{1}, \mathbf{i}}+\varepsilon_{1, i} \\
& d_{i}=\beta_{0}+\beta_{1} r_{i}+\beta_{2} \Delta_{i}+\beta_{3} \mathbf{X}_{\mathbf{i}}+\beta_{4} \mathbf{Z}_{\mathbf{2}, \mathbf{i}}+\varepsilon_{2, i} .
\end{aligned}
$$

In these equations, the rigidity of the price-setting mechanism $r$, and the duration of the contract $d$ are explained by each other, by a difference-in-difference variable $(\Delta)$, which identifies all contracts signed by electricity generators operating in restructured states after electricity market restructuring legislation was passed, by a set of control variables $(\mathbf{X})$, and a different set of instrumental variables $(\mathbf{Z})$, for each of the regressions. Finally, $\varepsilon_{1, i}$ and $\varepsilon_{2, i}$ are idiosyncratic error terms.

\subsection{Identification}

In what follows, our main goal is to estimate the impact of electricity market restructuring on the degree of price rigidity of procurement contracts and their duration. We use the variation over time and across U.S. states in the restructuring of the electricity market to identify the causal effect of changing regulation on procurement choices. As emerges from Table 2, only about half of the States passed legislation to deregulate their electricity markets. This peculiarity of the US experience provides us with the quasi-experimental set-up necessary to test whether the restructuring of the electricity market has lead to a change in the nature and the duration of the procurement contracts signed between generators and coal mines. By being able to use generators in non-restructured states as our control group, we are indeed able to isolate the effect of restructuring on the choice of procurement contracts in restructured states. This methodology is only justified, however, if we can convincingly argue, on the one hand, that the treatment choice, i.e. the decision to restructure, is exogenous to contract rigidity and duration, and, on the other hand, that absent restructuring, plants 
operating in states that did in fact restructure their electricity markets would have mirrored the behaviour of plants operating in non-restructured markets.

The first condition - i.e. the exogeneity of treatment - has been convincingly argued in a number of other papers that also use restructuring as a natural experiment (e.g., Bushnell and Wolfram, 2005; Fabrizio et al., 2007; Fowlie, 2010; Davis and Wolfram, 2012; Cicala, 2014). To summarize the arguments, the decision to restructure seems to be attributable to differences in natural resource endowments and to poor investments and contracting decisions made during the 1960s, 1970s, and 1980s (Joskow, 2003; Borenstein and Bushnell, 2000). Indeed, states which restructured generally had higher average electricity prices due to lack of hydroelectric generation and sunk investments in generation that had proven more expensive than expected - notably, nuclear and co-generation facilities (Joskow, 2003; Borenstein and Bushnell, 2000). One of the main reasons for restructuring was to improve investment decisions in new generation capacity, as opposed to improving existing generation, and transfer the risk from investment in new generation from consumers to electricity suppliers (Joskow, 2003; Bushnell and Wolfram, 2005). Furthermore, the belief is that electricity market restructuring would have eventually spread to the entire country had it not been for the California electricity crisis and Enron's financial collapse so that in theory the treatment would not have been contained to one "type" of state (Joskow, 2003).

It is obviously impossible to formally test the second condition discussed above given that the counterfactual is not observed. We are going to argue, however, that plants in the treatment and control groups exhibited similar behavior prior to the treatment (controlling for other confounding factors), and that the contracting behaviour of plants in the control group did not change as a consequence of electricity restructuring. ${ }^{24}$ We start with Figures 1 and 2. The figures describe how the rigidity and duration, respectively, of contracts signed by plants in the treatment group vary over the period of our analysis relative to the corresponding values for plants in the control group. ${ }^{25}$ Overall, both contractual rigidity and duration can be seen to evolve similarly over the pre-treatment period - i.e. before the passing of restructuring legislation - in restructured and in non-restructured states. This implies that the two groups exhibited similar trends before restructuring took place.

The second step in our argument is to verify that, net of common confounding factors, the observable characteristics of the control group have remained sufficiently stable over time. This would suggest that the control has not been affected by the treatment, or by other unobservable shocks, making it plausible to claim that, in the absence of treatment, the treated group itself would have developed similarly. A first look at the average rigidity and duration of contracts signed by control plants suggests that both indicators have continued to evolve during the treatment period along the same trend they exhibited prior to the start of electricity market restructuring (see Figure 3 and 4). This impression is supported by the summary statistics of the variables included in the empirical analysis that follows (Table 3). Overall the exogenous variables that are directly linked to the contractual behaviour appear quite stable over time for the control group as a whole, as shown in the last column of Table 3. The share of contracts written with a known counterpart, the characteristics of

\footnotetext{
${ }^{24}$ The assumption that the control group is not affected by the treatment, or "Stable Unit Treatment Value Assumption" (SUTVA) is crucial for a satisfactory 'experimental design' that allows a proper causal interpretation of the results (Rubin, 1980). We discuss this aspect at length later in the paper.

${ }^{25}$ Specifically, the figures plot the value of the estimated coefficient for each of the treatment-group vintage dummies for rigidity and duration, along with the corresponding $90 \%$ confidence interval around the estimates.
} 
the coal, the minimum amount contracted for, as well as the relative size of contract to the total quantity of coal sold (by the mine) and purchased (by the plant) are all not statistically different for the average control plant, before and after treatment. The one notable exception refers to the contractual treatment of sulfur, which can be seen to have radically changed across the samples. This is in all probability due to the introduction of the Acid Rains Program (ARP), whose first trading phase started in 1995. The need to submit emissions permits for each ton of $\mathrm{SO}_{2}$ released by large coal-fired power plants would quite obviously lead to significant changes in the approach to contracting in terms of the sulfur content of the fuel. Table 3 shows that the mean $Z$-score increased over time, underscoring this point. Intuitively, it makes sense for power plants to move towards contracts that give them a higher probability of receiving coal that would allow them to meet their ARP compliance targets. The need to source partially or totally different types of coal is further evidenced by the change in the provenance of coal shipped to control plants, who seem to have substituted higher-Btu, lower- $\mathrm{SO}_{2}$ Appalachian coal for lower grade Interior coal. This discussion leads us to conclude that, while it is important to control for the introduction of the ARP in our empirical analysis below, the overall behaviour of the control group as refers to their rigidity and duration choices seems to have remained consistent over time.

In light of our discussion so far, we conclude that the assumptions behind our identification strategy are supported by economic and historical arguments, as well as by the characteristics of our data. It seems appropriate, therefore, to causally attribute differences in procurement strategies observed between the treated and the control group after restructuring to the policy change itself. In a later section, we return to this crucial aspect by discussing the placebo tests we conducted, and a test of one possible deviation from the Stable Unit Treatment Value Assumption (SUTVA) assumption.

\subsection{Data}

To estimate equations (10) and (11) we use data derived from several sources. Our main source of information on coal procurement contracts is the Coal Transportation Rate Database (CTRB), which is taken from the Federal Energy Regulatory Commission (FERC) Form 580 "Interrogatory on Fuel and Energy Purchase Practices". The data are a representative survey of investor-owned, interstate electric generator plants with steam-electric generating stations with more than 50 Megawatts of installed capacity. Our database contains information on contracts signed for the years 1990-2001, including the price-setting mechanism specified in the contract and its duration, information on the lower and upper bounds for a number of coal quality attributes included in the contract, information on plant characteristics and identifiers for the county of origin of coal purchases. ${ }^{26}$

The data identifies contracts and any renegotiation of the contract, though this analysis only utilizes information for newly signed contracts. Information on changes to contract terms when a contract is renegotiated is not utilized here as the bargaining structure is quite different than the one modelled above. The data lists the contract as having one of seven types of price adjustment mechanisms: Base price plus escalation; Price renegotiation; Price tied to market; Cost-Plus with a fixed fee provision; Cost-Plus with an incentive fee provision;

\footnotetext{
${ }^{26}$ The dataset contain information on contracts signed previous to 1990 , however the coal market went through some large changes in the 1980s (see (Joskow, 1988) for more on these changes) which imply that contracts signed during this time will not be proper controls for contracts signed in the 1990s and beyond.
} 
Fixed price; Other. As detailed in Table 1, we code these contract types from 1 to 4 in increasing order of rigidity, and we drop the category "Other" ${ }^{27}$ The table also lists, for each contract type, the definition provided by FERC to plants in the survey's documentation. Duration is calculated subtracting the year the contract was signed from the expiration year indicated in the data.

In our empirical analysis we need to be able to discern the 'treated' plants in restructured states from the 'control' ones in states that did not restructure their electricity markets. Our theoretical priors, however, also tell us that the degree of market liberalization should also matter, as more 'intensive' treatments should lead to more marked effects in terms of their impact on procurement contracts. To capture the effect of the intensity of treatment, Post Restructuring, our difference-in-difference indicator of interest - i.e. $\Delta$ in the equations (10) and (11) - is a dummy variable that assumes the value of 1 for new contracts signed by electricity generators operating in restructured states after legislation was passed to restructure the electricity market, and a value of 2 when the retail side of the electricity market also began allowing competition. ${ }^{28,29}$ The argument for retail choice altering the competitiveness of wholesale markets relies on the fact that a monopolist retail supplier is more likely to source its electricity from within the firm than outside the firm. New retail suppliers, which generally do not have their own local generation, are more likely to purchase in the wholesale market based on price.(see, for example, Mansur, 2007)

We introduce a number of variables to control for changes to the regulatory environment and for idiosyncrasies in contractual relationships. To control for the passing into law of the Clean Air Act Amendments of 1990 and the introduction of the Acid Rain Programme (ARP), we include a dummy, called "Post $\mathrm{SO}_{2}$ Regulation", which takes the value of one for all contracts signed in 1991 or after and is zero otherwise. Furthermore, we identify plants involved in Phase I of the ARP by means of a "Mandatory Phase I Plant" dummy. A dummy was created to determine whether the plant and mine had written a contract previously. "Previous Interaction" takes the value of one if the plant and mine had already been involved in a contractual relationship with each other prior to signing the given contract and is zero otherwise. Finally, a "Restructured State" dummy was created which takes the value of one if a state ever restructures its electricity market and is zero otherwise. This allows us to control for structural difference between treated and control states.

Given the potential endogeneity problems due to the contemporaneous choice of rigidity and duration discussed above, one needs to choose appropriate instruments, i.e. variables that only affect one of the choice variables directly, while not directly impacting on the other. Our search for appropriate instruments is informed by our theoretical framework, and in particular by the discussion of the results of Proposition 2. In the process of proving Proposition 2, we showed that the choice of price rigidity is directly impacted by risk (i.e. by $\sigma_{e}^{2}$ and $\sigma_{x}^{2}$ in our

\footnotetext{
${ }^{27}$ Alternative forms of this ordinal ranking for rigidity were specified, and robustness checks conducted using these alternative dependent variables for $r$. The result were found to be qualitatively very similar. The full results of these tests are available from the authors upon request.

${ }^{28}$ To check the robustness of our results, we constructed an alternative difference-in-difference indicator which assumes a value of 1 for contracts signed by electricity generators operating in restructured states after restructuring legislation was passed and 0 otherwise. The change had little qualitative impact on the conclusions of the analysis. The full set of results are available from the authors.

${ }^{29}$ Ohio and Texas are two prime examples where the restructuring processes were different than in other states. Estimation of (10) and (11) were performed without Ohio and Texas separately. There was no qualitative difference for these estimations and the ones in the paper. The full set of results are available from the authors.
} 
model), whereas such parameters do not impact directly on the choice of duration. Conversely, the transaction cost-shifters $\mathbf{A}$ only directly affect the choice of duration. This leads us to identify variables that proxy for the actual degree of risk - such as the perceived variability of electricity prices and plants' exposure to input cost risk - as plausible instruments for rigidity. Transaction cost shifters - e.g., variables that provide information on relation-specific assets are, instead, good candidates as instruments for duration.

To capture the degree of price uncertainty faced by electricity generators, one would ideally use a measure of dispersion for the wholesale electricity price. For regulated markets, however, a wholesale price does not actually exist, and the so-called "system lambdas", which measure the marginal cost of production, while available for regulated markets are often not directly comparable to prices. As a result, for the sake of comparability between treated and control plants, we use the standard deviation of capacity utilization for gas and oil fired generators (Utilization Variability) to measure the degree of price uncertainty by electricity generators. The rationale for this approach is simple: plants which are primarily fired with oil and gas represent the high-cost technologies for producing electricity over the sample we analyze. As such, they would be utilized only under conditions of high demand, which are associated with high prices for electricity. Hence, the variability in the utilization of oil and gas-fired plants proxies for the variability in the price of electricity, $\sigma_{e}^{2}$. To proxy for input-cost risk, we first include an indicator for whether the mine is an underground mine (Underground Mine), and then create dummies that control for provenance of coal using the coal-producing regions defined by the Energy Information Administration (EIA), and include "Interior Mine" and "Western Mine" in our regressions. ${ }^{30}$ The understanding here is that, since both the physical characteristics of coal seams and mining practices differ across basins, underground mines and mines in different basins have different cost structures. Besides this rather crude measure of input-cost risk, we also want to include measures that take into account the match between coal characteristics and boiler types. Indeed, when plants write a contract with mines for monthly delivery of coal, they specify the limits of attributes that are acceptable for deliveries. As pointed out by Crio and Condren (1984) and Kerkvliet and Shogren (1992), however, plants often use long-term contracts to procure coal with attributes that match the design parameters of their boiler, so that the attributes specified in the contract are a function of the technical characteristics of the boiler, and as such can be deemed exogenous to the procurement choice. ${ }^{31}$ Thus, the degree of input-cost risk a plant is exposed to is a function of both the physical characteristics of the available coal and of the technical characteristics of the plant. To capture these aspects we include $Z$-scores for different coal attributes (Z-Ash, Z-Btu, Z-Sulfur) for each Bureau of Mines coal producing district. The $Z$-score - i.e. the difference between the allowable level of an attribute and the mean value of that attribute for coal mined in the district, divided by the standard deviation of the attribute at the district level - measures the probability that the average mine in the district is able to deliver coal that meets the plant's technical requirements.

As empirical counterparts for the shifters of the transaction cost functions in the theoretical model, we focus on variables that might proxy for the likelihood of breach of contract, in

\footnotetext{
${ }^{30}$ The omitted category refers to mines located in Appalachia.

${ }^{31}$ Generally, in long-term contracts the maximum (minimum) levels of attributes such as ash, sulfur, moisture, and heat (Btu) that are allowed are specified. Ash, sulfur, and moisture are undesirable attributes, therefore specifying lower maximum levels of these attributes in a contract imply the requirement to source higher quality coal. Btu's, on the other hand, are a positive attribute; therefore a higher minimum level specified implies a higher quality coal.
} 
particular we consider variables that proxy for the availability of alternative contracting partners and for the relative importance of a specific contract to each of the parties (Joskow, 1987; Kerkvliet and Shogren, 2001; Kozhevnikova and Lange, 2009). As discussed in Section 3 , factors that increase the availability of alternative options might be correlated with a shorter contractual duration, whereas higher levels of dedicated assets ought to be correlated with longer contracts. The instruments we use for this purpose are: proxies for the level of dedicated assets that both the plant and the mine have in the relationship at the time of the first delivery ("Plant Dedicated Assets" and "Mine Dedicated Assets", respectively), calculated as the ratio of an individual contract quantity to the sum of the plant's (mine's) overall contract quantity ${ }^{32}$; the minimum quantity of coal to be transacted each month, "Minimum Quantity"; and a dummy that indicates whether the plant can receive deliveries through multiple modes of transportation, "Multiple Mode of Delivery". The "Multiple Mode of Delivery" dummy is a good candidate as an instrument for duration because it is clearly exogenous to the rigidity decision being the outcome of previous investment decisions and as such predetermined. Moreover, the possibility to receive coal deliveries using multiple means of transportation makes the plant less dependent on any given supplier, and thus affects the optimal choice of contractual duration. The remaining instruments are also likely correlated with a predetermined variable, the plant's output rating (i.e. its productive capacity). The reason for this is that most long-term contracts signed between mines and coal-fired power plants specify a minimum take linked to the productive capacity of the boiler. As mentioned in Section 2, coal-fired plants tend to be targeted at base-loads and operate continuously. Since coal is bulky and storage capacity limited, one of the main concern of coal-fired generators is not to run out of fuel. As productive capacity is given at the time the contract is signed, it is likely to be uncorrelated with the rigidity decision. On the other hand, the relative importance of a given contract to both mine and plant influences the stability of the contractual relation, as the parties are less likely to walk away from a large contract. Thus, the probability of a breach of contract decreases with the minimum take, as does, for the reasons discussed in Section 3, the marginal cost of duration. One would then expect duration to be positively correlated with minimum take. Thus, our theoretical priors suggest that all the instruments mentioned above should be both exogenous and relevant. ${ }^{33}$

As pointed out by Ackerberg and Botticini (2002), one concern that emerges when empirically estimating the determinants of contract choices via reduced-form regressions that use sellers' and buyers' characteristics is that, if these characteristics are imperfectly measured, and if buyers and sellers are not randomly matched, a simple OLS approach risks providing biased estimates. Our theoretical insights do not depend on how sellers and buyers are matched, in the sense that, irrespective of the matching procedure, an increase in the degree of market liberalization would lead to more rigid, shorter contracts. There are reasons, however, to believe that in reality the matching between mines and plants does depend on some of the characteristics of the agents. For example, one would intuitively think that plants operating in high-risk environments have stronger preferences for rigid contracts relative to plants facing less volatile output prices, while low-cost-volatility mines would not dislike rigid

\footnotetext{
${ }^{32}$ As the data does not contain a mine identification code, a county of coal origin code is used instead.

${ }^{33} \mathrm{~A}$ number of other instruments with similar characteristics are available to us. We have information on whether the plant owns the transportation equipment used to deliver coal, the number of mines active in the county the contracted coal is being shipped from, and finally, the boiler rated output. We use these instruments both as an alternative to and in combination with the ones discussed in the main text. The results of our instrumental variable estimates are extremely robust to the choice of instrument. The full set of alternative results is available from the authors.
} 
contracts quite as much as mines that experience large shocks to their extraction costs. As a consequence, it is easy to imagine that some form of assortative matching occurs between high-risk plants and low-risk mines. To alleviate the potential endogeneity issues, we follow Ackerberg and Botticini (2002) and introduce a 'matching' equation which regresses our proxy for revenue uncertainty, Utilization Variability, on a set of destination state dummies, and the same dummies interacted (as appropriate) with our proxies for extraction cost volatility (Z-Ash, Z-Btu, Z-Sulfur, Underground Mine, Interior Mine, and Western Mine). The predicted values of Utilization Variability are subsequently included in the estimation of equations (10).

\subsection{Results}

Tables 4 and 5 report the results of the estimation of equations (10) and (11), respectively. In each table we first present a benchmark model, which does not correct for endogeneity. We then discuss models that use an instrumental variable approach to control for the simultaneity of the rigidity and duration decision. Finally, the results from a system estimation of the rigidity and duration equations are presented. Furthermore, in Table 4 we present results that assess the sensitivity of our conclusions to biases induced by the endogeneity of the match between sellers and buyers, à la Ackerberg and Botticini (2002). Standard errors are either clustered at state level to correct for potential state-level serial correlation, or bootstrapped as appropriate.

The results of Table 4 support the theoretical predictions of Proposition 1: electricity market restructuring does lead to the signing of more rigid contracts (see Hypothesis 1). This result emerges as a robust finding of our analysis across all specification as the coefficient of the Post Restructuring dummy is everywhere positive, stable in magnitude, and always significant. Another aspect to clearly emerge from Table 4 is that our regressions show that rigidity and duration are substitutes at the optimum. The coefficients on Duration are indeed negative throughout and statistically significant in all specifications. The coefficient is fairly stable when moving from a specification that does not correct for the endogeneity to one that does, only varying in magnitude when rigidity is treated as continuous as opposed to ordinal, implying little endogeneity bias. The $F$-test for excluded instruments in the first stage is highly statistically significant across all four specifications that instrument for duration. Based on Column (3), a series of tests for the validity of our instruments are conducted. Hansens test fails to reject the null that the instruments are valid $(J$-test $=5.54$, $p$-value $=0.14$ ), and the model passes both the Kleinbergen-Paap underidentification test (LM statistic $=15.09, p$-value $=0.00)$ and the Kleinbergen-Paap Wald test for weak identification $(F$-test $=10.64)$. The results of these tests confirm that the instruments we use are both valid and relevant. ${ }^{34}$ In Column (4) we also instrument for Utilization Variability to control for the possibility of an endogenous match between mines and plants. The coefficient on Utilization Variability switches sign, but remains statistically insignificant. The other coefficients in the regression, including Post Restructuring, are largely unaffected by this procedure. We conclude that the endogenous nature of the matching does not represent a problem in terms of our main objective, which remains to assess the impact of electricity

\footnotetext{
${ }^{34}$ To test the robustness of our results, we replicated these results with subsets of the current variables, and including the other variables described in Footnote 33. The results, available from the authors, qualitatively confirm our conclusions.
} 
market restructuring on the degree of contractual price rigidity agreed by the parties.

The signs of the coefficients of the other controls conform to our theoretical expectations. Recall that higher levels of Z-Ash and Z-Sulfur - as well as lower levels of Z-Btu - are associated with lower uncertainty, as the mines operating in the specified district are more likely to be able to deliver coal that meets the boiler's technical specifications. The same mines ought to more willing to sign relatively more rigid contracts, given that they face less risk. This intuition is confirmed by the estimated coefficient of Z-Ash, Z-Sulfur, and Z-Btu, all of which have consistently the expected sign, even if they are not always statistically significant. Since underground coal is more costly to extract and underground mines face higher probability of industrial accidents, one would expect that mines extracting coal from pits would be more reluctant to sign rigidly priced contracts. As expected, the coefficient's estimates for Underground Mineare consistently negative, albeit significant in only one instance. Appalachian mines have more challenging technical problems and have traditionally had a more unionized work-force, thus they are both more risky and more exposed to macroeconomic shocks that may affect the labor market, relative to Interior and Western mines. Accordingly, the coefficients for both Interior Mine and Western Mine are expected to be positive as these mines are much less exposed to the kind of shocks discussed above, and hence more likely to accept rigidly priced contracts. The relevant coefficients are all positive and, at least for Western Mine, statistically significant across all specifications. Finally, the coefficient of the Utilization Variability variable, which proxies for the volatility of the price of electricity, is always statistically insignificant. Once the endogeneity of the matching between sellers and buyers is controlled for, however, as in Column (4) of Table 4, the coefficient, while remaining statistically insignificant, becomes positive, which is the theoretically expected sign.

Table 5 shows the results from the estimation of the duration equation, (11). The first column does not control for the possible endogeneity of rigidity, while the other columns attempt to control for it using instruments that proxy for input-cost and output-price risk. Our strategy for the selection of instruments here deserves some discussion. In Table 5 we report IV estimates of equation (11) carried out using the complete set of instruments we discussed in Section 4.2 above, i.e. Z-Ash, Z-Sulfur, Z-Btu, Western Mine, Interior Mine, Underground Mine and Utilization Variability. These instruments as a set comfortably pass Hansen's $J$ test for exogenity $(J$-test $=7.73, p$-value $=0.26)$, and perform reasonably well in terms of the tests for under-identification and for weak identification. ${ }^{35}$,Some concerns, however, arise from the $F$-statistic of the test for the relevance of the instruments we present in Column (2). The reported value of 4.34 is indeed some way from the recommended value of 10. In order to gauge the validity of our instruments, we experimented with all possible combinations of the original instruments. The only case for which we obtain an $F$-test in excess of 10 is in the exactly identified model which uses Western Mine as the only instrument (see Column (3) of Table 5). In this case, the $F$-test for excluded instruments in the first stage is 12.00 , the Kleibergen-Paap $\chi^{2}$ LM statistic is 8.55 ( $p$-value $\left.=0.00\right)$, and the Cragg-Donald Wald $F$-statistic equals 36.68 . Since in this case we are unable to compute Hansen's over-identification statistic, we compute the $J$-statistic for the next best model for which we can test for the orthogonality of Western Mine in isolation. This model is the one which uses Western Mine, Z-Sulfur, and Interior Mine as instruments for rigidity. In this case the $J$ test statistic for the joint test of over-identification of all instruments

\footnotetext{
${ }^{35}$ The Kleibergen-Paap LM statistic is 12.71 , and its $p$-value 0.0795
} 
equals 0.14 ( $p$-value $=0.93)$, whereas the $C$-statistic for the orthogonality of Western Mine is 0.099 ( $p$-value $=0.75)$. We conclude that Western Mine is a valid instrument for rigidity. Columns (4) and (5) present the results of the IV procedure which uses only Western Mine as an instrument for rigidity, when we take into account the fact that Duration is a positive variable and Rigidity a categorical variable.

The Post Restructuring results are in line with the implications of our theoretical analysis see Hypothesis 2 - as it is generally not statistically significant. One potential concern in this context is that other authors (e.g. Joskow, 1987; Kerkvliet and Shogren, 2001; Kozhevnikova and Lange, 2009) have shown that duration of contracts has been falling over our sample period - indeed the time control variables are statistically significant and negative in sign. Against this backdrop, the identification of a further decrease in duration for contracts signed by restructured plants might be difficult.

Rigidity is generally statistically significant and negative and instrumenting for rigidity, Columns (2)-(4), leads to a larger negative coefficient. This is consistent with our theoretical insights that rigidity and duration are substitutes at the optimum. Overall, however, the changes are of no great consequence in terms of our key question here, as the effect of electricity market restructuring on contractual duration, while slightly larger, remains mostly insignificant. This result is robust to the changes in the set of instruments discussed above. The costs shifters discussed in Section 4.2 appear here as controls for Duration. Mine Dedicated Assets and Minimum Quantity have the correct sign and are statistically significant in all specifications. Plant Dedicated Assets has the correct sign throughout but is not statistically significant, while the sign for Multiple Mode of Delivery is the opposite of what one would have expected. Indeed, our intuition would suggest that the easier it is for the plant to have coal delivered from alternative sources, the less stable the contractual relationship, the shorter the contract.

\subsection{Discussion}

The results presented thus far confirm our theoretical insight that in response to changes in the market environment that expose them to more output-price risk, coal-fired power plants will strive to introduce more rigid pricing in their procurement contracts, to limit their exposure to input-price risk. A closer inspection of Figure 1, however, reveals a difficulty with our analysis. There, the difference between contractual rigidity in treated and control states becomes statistically significant only with a pronounced lag. To explain this aspect of our results, we need to take into account that the deregulation legislation was staggered over time, so that the red line in the figure is only indicative of the beginning of treatment in some states. In the figure, the average rigidity is computed pooling all contracts signed by plants in deregulated states, so that contracts of the same vintage signed after 1996 may in fact be contracts signed in already-deregulated states and in not-yet-deregulated ones. To properly account for these lags in deregulation, we create an alternative version of Figure 1, this time including dummies that measure time relative to the year of deregulation, rather than calendar time. In this way we obtain the estimates reported in Figure 5. The graph confirms that contractual rigidity increases immediately after deregulation. Interestingly, Figure 5 also suggests that, following deregulation, plants and mines have entered a phase of learning about the design of an optimal contract. Indeed, the degree of contractual rigidity is shown to increase with the passage of time after deregulation. 
A further remark on the rigidity regressions is in order. Fowlie (2010) suggests that restructured plants may have chosen not to undertake new capital investment to comply with the $\mathrm{NO}_{x}$ Budget Programme, preferring to alter the type of coal they contracted for. If fuel switching lead power plants to contract with mines with lower extraction cost risk, and thus lower aversion for rigidity, it might have been the cause of the increase in contractual rigidity that we identify in Table 4 . In other words, it would be the $\mathrm{NO}_{x}$ Budget Programme, not restructuring to cause the increase in rigidity. For this to be a convincing explanation, however, we should observe a significant shift in the geographical origin of the coal sourced by regulated plants. As seen in Table 3, however, the distribution of contracts signed across the three coal basins is constant for the restructured plants before and after restructuring. ${ }^{36}$ Additionally, as discussed above, once the timing of deregulation is properly accounted for, the contractual rigidity can be shown to increase immediately once deregulation is implemented. This means that for the first deregulated states the changes in contractual rigidity pre-date the introduction of the $\mathrm{NO}_{x}$ Budget Programme by at least four years. ${ }^{37}$ Furthermore, in the rigidity equation we control for potential differences in mine's preferences for rigidity with the $Z$-scores, a coal basin dummy, and an Underground Mine dummy.

As in any 'quasi-experimental' setting our challenge lies in convincingly attributing the observed changes in behavior to the treatment. While our discussion of the identification strategy in Section 4.1 goes a long way towards justifying our research design, in the interest of completeness we also want to rule out to the extent possible, that the results obtained above are purely due to chance. We then perform a so-called 'placebo test' whereby, after dropping the treated observations from the sample, we randomly allocate states to two groups, the placebo group and the control group. This reassignment completed, we replicate our analysis above and test whether the coefficient of the placebo indicator is statistically significant. Failure to reject the null that the coefficient is actually zero would suggest that the relative increase in price rigidity we observe in the data is in fact due to the effect of the treatment.

The two panels in Figure 6 presents the distribution of coefficient estimates for the rigidity (a), and the duration regression (b), respectively, obtained replicating the experiment described above 10,000 times. At each iteration a new random assignment of States to the placebo and control groups is performed, and the model re-estimated using the same instrumental variable procedures as in Table 4, column (3), and Table 5, column (3). As can be clearly appreciated, we cannot reject the null that both coefficients are indeed statistically insignificant. The procedure thus supports our conclusion that the increase in price rigidity for contract signed by plants in restructured states we observe in the data is indeed due to the treatment, and not to mere chance.

One final concern with the kind of study we are conducting is that the treatment might somehow spill over to the control group, thus invalidating the SUTVA. In our study, the units we use to form the control estimates participate in the coal market alongside treated ones. In particular, some of the mines in our data set might be at the same time contracting with plants in restructured states and with others that operate in regulated markets. One might suspect, for example, that a mine that is forced into more rigid contracts by its customers in

\footnotetext{
${ }^{36}$ The $t$-statistics, and the associated $p$-values, for the tests for difference in means across different coal basins, before and after treatment are: Appalachia, $t=0.26, p$-value $=0.79$; West, $t=0.10, p$-value $=0.92$; Interior, $t=-0.72, p$-value $=0.47$.

${ }^{37}$ The first restructuring laws were implemented in 1996, whereas the US Court of Appeals upheld the $\mathrm{NO}_{x}$ Budget Programme in early 2000. The deadline for full compliance was set for May 2004.
} 
deregulated markets might try to compensate by pushing for less rigid contract with its other, regulated, customers than it would otherwise have done in the absence of the treatment. In this case, our estimates of the effect of the treatment on the treated would be biased upwards. To test for such treatment spillovers, we identify mines ${ }^{38}$ that sell coal to both regulated and unregulated plants and test whether their behavior is anyway different from the behavior of mines that only sell coal to regulated plants. Table 6 reports the results of this procedure. The variable of interest here is the indicator discussed above, "Mine Selling to Both Plant Types", which emerges consistently as insignificant across all specifications. We conclude that, at least as refers to this potential spillover channel, the SUTVA seems to hold. While we have no theoretical priors on how the treatment might spill over in terms of our duration regressions, we perform the same test for duration, for the sake of completeness. Also in this context mines that operate across different regulatory regimes are shown not to behave differently when negotiating with plants in regulated states, relative to mines that only sell to such plants. Once again, these results support the SUTVA. ${ }^{39}$

\section{Contract changes, mining efficiency, and transaction costs}

Our theoretical discussion and empirical evidence so far have illustrated that restructuring in the downstream market has real effects on the contractual behavior of parties upstream. In particular, the move to more rigidly priced contracts emerges prominently from both the theoretical and empirical analysis. In what follows, we address the implications of more rigid contracts discussed in section 3.5.

\subsection{Productivity}

We start by discussing Hypothesis 3, namely that changes in contractual rigidity, by changing the incentives for cost reducing effort on the part of mines, might lead to increases in mining efficiency. Our findings that plants in restructured electricity markets sign contracts characterized by more rigid price adjustment mechanisms are interesting per se since they highlight a novel channel through which market restructuring affects firms' behavior. Even more interesting, however, is the question whether such changes would push coal mines to improve their efficiency. To test this proposition, we use again a difference-in-difference design. The model is,

$$
p_{i, t}=\zeta_{i}+\gamma_{1} \Sigma_{i, t}+\gamma_{2} \mathbf{X}_{\mathbf{i}, \mathbf{t}}+\varepsilon_{i, t}
$$

where $p_{i, t}$ is county $i$ 's coal mines average labor productivity in year $t, \zeta_{i}$ is the county fixed effect, $\Sigma_{i, t}$ is the difference-in-difference variable indicating whether a mine sold coal under a new contract to a plant in a restructured state after restructuring legislation was passed, $\mathbf{X}_{\mathbf{i}, \mathbf{t}}$ is a set of control variables, and $\varepsilon_{i, t}$ an idiosyncratic error term. ${ }^{40,41}$ County $i$ 's coal mine

\footnotetext{
${ }^{38}$ As discussed above, in the absence of mine identification codes, we resort to the county-of-coal-origin code, instead.

${ }^{39}$ The full set of results relative to the duration regressions is available from the authors upon request.

${ }^{40}$ The data used in the estimation of (10) are derived from a representative sample of all contracts, and are too few per mine-year to use in this analysis. As a result, we cannot use the rigidity of the price adjustment mechanism directly here. The data utilized for this estimation is the population of transactions between plants and mines, and it allows a full picture of the impact on mines of selling coal to restructured plants.

${ }^{41}$ Data on plant purchases does not link to a specific mine but rather links to the county of origin. This is the level utilized in the productivity analysis.
} 
labor productivity, $p_{i, t}$, is measured as the average number of short tons of coal produced per mine employee in any given year by mines located in the county $i$. The data is taken from the Mine Health and Safety Administration (MHSA) Part 50 Address/Employment Dataset. The difference-in-difference variable, "Coal to Restructured State", equals one if any of county $i$ 's mines sold any coal, under a new contract to a plant located in a state that had passed restructuring legislation and is zero otherwise. This specification is consistent with the difference-in-difference variables used in equations (10) and (11). Information on sales of contract coal is taken from the FERC 423 dataset. As control variables we use the number of injuries per worker in year $t$, and its squared term, a variable indicating the proportions of mines in the state-county that have been producing continuously (i.e. they did not shut down) during year $t$, and its squared term, together with year dummy variables. "Injuries per worker" and "Continuous Production" data, also come from the MHSA Part 50 Address/Employment Dataset.

To support our identification strategy we refer back to the discussion in Section 4.1, as far as the exogeneity of treatment is concerned, and focus here on the appropriateness of the control group. First, we focus on the stability of the trend in the control group. Figure 8 graphs the average productivity of mines in our control group over the time horizon of our analysis. The series doesn't exhibit any break or a change in trend once the legislation is passed. ${ }^{42}$ Second, we concentrate on the comparability of the treatment and control groups. Figure 7 plots the evolution of labor productivity for mines which sold coal under a new contract to plants in restructured states after restructuring (the treatment group), relative to the productivity of mines that never sold to a plant in a State that eventually deregulated (our control group). ${ }^{43}$ The labor productivity for the two groups trends similarly before any restructuring legislation is passed. Overall the evidence justifies our causal interpretation of changes in productivity as being driven by deregulation.

Table 7 shows the results of the estimation of equation (12). According to our results, controlling for other determinants of productivity, mines that sell coal to plants in restructured states are on average $11 \%$ more productive than the control group. This finding supports the argument that the move to higher-powered incentives in contracts written by restructured plants lead to an increase in productivity by mines.

Similarly to what is seen for rigidity, Figure 7 shows that the labour productivity of treated mines, rather than deviating significantly from the productivity of the control ones on impact - that is as soon as the treatment becomes effective - becomes significantly larger only with a lag of two years, and then strongly so with an even longer delay. Two aspects might be driving this result. First, counties are recruited to the treated group as soon as one mine in the county signs a new contract with a power plant operating in a state that has introduced deregulation legislation, irrespectively of the amount of coal being contracted and of the relative importance of the contract in the total output of the county. Evidently, it might be the case that initially only a limited share of the mines and a small fraction of the total coal extracted in any given county is sold under more rigid contracts, so that the effort-inducing impact of the new contracts gets diluted. As more and more mines in each of the treated

\footnotetext{
${ }^{42}$ Coal productivity across the whole industry dropped in 2001 after increasing throughout the 1990s and in 2000 (U.S. EIA, 2010). The decrease shown for the control in Figure 8 is even stronger in the treatment group. Indeed, Figure 7 shows that the productivity of the treatment group as a whole decreases in 2001 relative to 2000 .

${ }^{43}$ To be more precise, the figure plots the estimated coefficients for the treatment-group specific year dummies, along with the corresponding $90 \%$ confidence interval around these estimates.
} 
counties sign new contracts with deregulated plants over time, however, the changed nature of the contractual relationship starts having more marked impacts, and gradually the change in productivity becomes statistically significant. Secondly, as discussed in Section 4.3, we find evidence of a rather steep learning curve faced by plants and mines after deregulation so that the rigidity of contracts in treated states increases over time (see Figure 5). As rigidity increases, the efficiency-inducing incentives for the mines become stronger. Hence, the gradual increase in rigidity over time might be a further contributing factor in explaining the lag in productivity increases noted above.

Our results on productivity gains, besides being in line with economic theory, are also consistent with the evidence discussed by both Cicala (2014) and Chan, Fell, Lange, and Li (2013), that plants in restructured states pay a statistically lower price for their coal. Indeed, more efficient mines would be able to provide coal at lower prices. Interestingly, even the magnitude of the coefficient of restructuring on coal mine productivity in Table 7 is consistent with the drop in coal prices found in Cicala (2014) and Chan et al. (2013). Cicala (2014) finds a $12 \%$ drop in coal prices, while Chan et al. (2013) estimate the drop to be closer to $10 \%$, both of which are broadly in line with our results. Neither of these papers, however, explicitly discusses the mechanism that could have lead to lower coal prices. Our analysis suggests that the increased price rigidity of contracts due to restructuring could be the mechanism behind this drop in prices. By introducing higher-powered incentives for cost savings, changes in procurement contracts might have brought about productivity increases, and ultimately the decreases in prices documented in the literature.

Cicala (2014) notes that plants in restructured states are more likely to switch to out-of-state coal mines to procure fuel, and that after divestiture the labour content of coal purchased by plants in restructured states decreases. These findings suggest an alternative explanation for our results here. It is indeed possible that the increase in productivity we report in Table 7 might be linked to the sorting of highly productive mines into contracts with plants in restructured states, and low productivity mines with plants in traditionally regulated states, a change that need not imply any actual productivity gain. If our results were being driven by such a re-ordering of mines, however, we would expect to find evidence that some mines that previously were not selling coal to plants in restructured states would start doing so, after restructuring. In our dataset, however, we could find no county whose mine were not initially selling to a plant in a would-be restructured state that started after treatment commenced. A more subtle way to test Cicala's hypothesis is to look at mines (counties) that stopped shipping coal to restructured markets after restructuring took place (the 'discontinuing' group), and compare their productivity levels with those of mines that kept selling even after restructuring (the 'continuing' group). According to the sorting hypothesis, the latter group should exhibit higher productivity levels in the period before restructuring. Using our data, we can test the (one-sided) hypothesis that the average labour productivity of the continuing firms is higher than that of the discontinuing ones. Table 8 presents the results of the test for the difference in means across the two samples, between 1991 and 1995, the year before the first treatment period begins. The test results suggest that there is no statistically difference in the level of productivity between (groups of) mines that stopped selling to restructured states, and those who, instead continued selling there. We conclude that the type of sorting hypothesizes by Cicala (2014) is unlikely to be driving our results. 


\subsection{Renegotiations}

Against the possible gains due to the improved productivity highlighted above, one needs to weigh the possible losses due to changes in procurement contracts. In particular, one aspect often discussed in the literature is the fact that more rigid contracts are more costly to negotiate and prone to more frequent renegotiations (Tadelis and Williamson, 2012). Thus, the increase in contract rigidity identified in Section 4.3 could imply an increase in transaction costs. While it is not possible, given the available data, to gauge directly whether transaction costs have increased, one possible - albeit indirect - test of this hypothesis is to test whether more rigid contracts are actually renegotiated more frequently. To analyze the effect of contract rigidity on renegotiation, we estimate the following model:

$$
m_{i}=\theta_{0}+\theta_{1} r_{i}+\theta_{2} d_{i}+\theta_{3} \mathbf{X}_{\mathbf{i}}+\varepsilon_{i}
$$

where $m_{i}$ is the time to the first renegotiation of the contract, $r_{i}$ and $d_{i}$ are the rigidity of the price adjustment mechanism and the intended contractual duration of contract $i, X_{i}$ is a vector of control variables, and $\varepsilon_{i}$ is an idiosyncratic error term.

Table 9 shows the results of the estimation of equation (13) performed using a poisson model. A more rigid price adjustment mechanism is associated with a shorter time until the first renegotiation of the contract, whereas a longer contractual duration has the opposite effect, increasing the number of years until first renegotiation.

These results conform to our theoretical priors. A more rigid pricing mechanism, by exposing the mine to the full cost of adverse realizations of extraction costs, tends to make the contractual relationship more vulnerable vis-à-vis such shocks. This evidence is suggestive of the fact that restructuring could have harmful effects in as far as frequent renegotiations imply an increase in the industry-wide transaction costs.

\section{Conclusions}

A substantial body of literature attempts to assess the economic impacts of electricity market restructuring. This literature, however, mostly focuses on how deregulation impacts directly on the regulated entities. In this paper we break with this tradition and analyze the consequences of deregulation on the contractual relationships that characterize the supply chain upstream from the deregulated market. Our analysis suggests that this previously overlooked aspect of deregulation might have substantial welfare implications.

During the 1990s, a number of U.S. states restructured their electricity market so that power generators could no longer be assured of cost recovery or a dedicated buyer for their output. Restructuring thus increased the uncertainty such plants operated under, as they then needed to compete to sell electricity and could not be guaranteed an output price. We have presented a theoretical discussion of the likely impact of these changes on the optimal choice of procurement contracts. Our analysis predicts that plants would respond to the increased uncertainty by signing contracts for coal delivery with a more rigid price adjustment mechanism. In our model, the use of a more rigid price adjustment mechanism reduces the plant's exposure to uncertainty in upstream prices, offsetting the downstream increase in uncertainty. Our empirical analysis uses coal contracts data spanning the period 1990-2001 
and finds evidence that strongly supports our theoretical predictions.

One effect of the change to a more rigid price adjustment mechanism is that it provides higherpowered cost-reduction incentives to the upstream supply chain, coal mines in this instance. Results here show that these increased incentives did lead to a significant improvement in coal mine productivity. Our estimate of the magnitude of this increase in productivity is very close to the estimated reduction in coal prices recently discussed by Cicala (2014) and Chan et al. (2013). We argue that the evidence provided here can be seen as the mechanism behind the price reductions found by these authors.

On the other hand, transaction costs economics points out that more rigid price adjustment mechanisms entail higher transaction costs, both in terms of the initial negotiation costs and in terms of more frequent renegotiations and more likely breaches of contract. One might quite naturally be concerned that the productivity improvements discussed above could be offset by changes in the transaction cost associated with the more rigid contracts being signed. To assess this aspect, we estimated the impact of price rigidity on the time to first renegotiation for the contracts in our sample. Our findings reveal that a more rigid price adjustment mechanism is indeed associated with a shorter time to first renegotiation, providing an empirical basis to our concerns.

The implications of our research are far-reaching. Until now, the empirical work on the effects of deregulation has largely ignored the impacts of the deregulation process upstream. In this paper we demonstrate that there are reasons to suggest that such omission is potentially of significance from the point of view of the analysis of the efficiency of the industry. The potential for efficiency spillovers upstream of the deregulated sectors could be as large as the gains from deregulation to the deregulated sector. Cicala (2014), for example, estimates that the aggregate cost savings from the decreased fuel price might be as large as 1 billion dollars per year. The potential for upstream efficiency spillovers is also interesting from an equity standpoint. The goal of deregulation is for the efficiency improvements to flow to consumers, however it is certainly possible that these gains stay within the deregulated sector. Clearly, more work is needed to assess the net impact of deregulation on efficiency in the upstream market.

\section{References}

AckerberG, D. And M. Botticini (2002): "Endogenous Matching and the Empirical Determinants of Contract Form," Journal of Political Economy, 110, 564-591.

Allen, D. W. And D. Lueck (1992): "Contract Choice in Modern Agriculture: Cash Rent versus Cropshare," Journal of Law and Economics, 35, 397-426.

(1995): "Risk Preferences and the Economics of Contracts," American Economic Review, 85, 447-451.

Asker, J. And E. Cantillon (2010): "Procurement when Price and Quality Matter," RAND Journal of Economics, 41, 1-34.

Bajari, P. and S. Tadelis (2001): "Incentives versus Trasactions Costs: A Theory of Procurement Contracts," RAND Journal of Economics, 3, 387-40. 
Baron, D. P. (1970): "Price Uncertainty, Utility, and Industry Equilibrium in Pure Competition," International Economic Review, 11, 463-480.

Borenstein, S. And J. Bushnell (2000): "Electricity Restructruing: Deregulation or Reregulation," Regulation, 23, 46-52.

Borenstein, S., J. Bushnell, And F. Wolak (2002): "Measuring Market Inefficiencies in California's Restructured Wholesale Electricity Market," American Economic Review, 92, 1376-1405.

Buessing, M. And D. Weil (2014): "Impact of Contracting on Occupational Injuries and Fatalities in Underground Coal Mining," Mimeo.

Bushnell, J. And C. D. Wolfram (2005): "Ownership Change, Incentives and Plant Efficiency: The Divestiture of U.S. Electric Generation Plants," Center for the study of energy markets wp 140, University of California at Berkeley.

Chan, H. S., H. Fell, I. Lange, and S. Li (2013): "Efficiency and Environmental Impacts of Electricity Restructuring on Coal-fired Power Plants," mimeo, University of Maryland.

Che, Y.-K. (2008): "Procurement," in The New Palgrave Dictionary of Economics Online, ed. by S. N. Durlauf and L. E. Blume, Palgrave Macmillan.

Cheung, S. (1969): "Transaction Costs, Risk Aversion, and the Choice of Contractual Arrangements," Journal of Law and Economics, 12, 23-42.

Chiappori, P. And B. Salanié (2002): "Testing Contract Theory: A Survey of Some Recent Work," in Advances in Economics and Econometrics, ed. by M. Dewatripont, L. Hansen, and S. Turnovsky, Cambridge University Press.

Cicala, S. (2014): "When Does Regulation Distort Costs? Lessons from Fuel Procurement in U.S. Electricity Generation," American Economic Review, forthcoming.

CoAse, R. (1937): "The Nature of the Firm," Economica, 4, 386-405.

Corts, K. S. And J. Singh (2004): "The Effect of Repeated Interaction on Contract Choice: Evidence from Offshore Drilling," The Journal of Law, Economics, and Organization, 20, 230-260.

Crio, M. And A. Condren (1984): "Which Coal at Which Cost?" Public Utilites Fortnightly, $113,32-36$.

Davis, L. And C. D. Wolfram (2012): "Deregulation, Consolidation and Efficiency: Evidence from U.S. Nuclear Power," American Economic Journal: Applied Economics, 4, $194-225$.

Davis, L. W. And L. Kilian (2011): "The Allocative Cost of Price Ceilings in the U.S. Residential Market for Natural Gas," Journal of Political Economy, 119, 212-241.

Fabrizio, K., N. Rose, And C. D. Wolfram (2007): "Do Markets Reduce Costs? Assessing the Impact of Regulatory Restructuring on US Electric Generation Efficiency," American Economic Review, 97, 1250-1277. 
Fowlie, M. (2010): "Emissions Trading, Electricity Restructuring, and Investment in Pollution Abatement," American Economic Review, 100, 837-869.

Gross, R., W. Blyrth, and P. Heptonstall (2010): "Risks, Revenues, and Investment in Electricity Generation: Why Policy Needs to Look Beyond Costs," Energy Economics, $32,796-804$.

Holthausen, D. M. (1979): "Hedging and the Competitive Firm Under Price Uncertainty," American Economic Review, 69, 989-995.

Joskow, P. (1985): "Vertical Integration and Long-Term Contracts: The Case of CoalBurning Electric Generating Plants," Journal of Law, Economics, $E_{3}$ Organization, 1, 33-80.

(1987): "Contract Duration and Relationship Specific Investments: Empirical Evidence from Coal Markets," American Economic Review, 77, 168-185.

(1988): "Price Adjustment in Long-Term Contracts: the Case of Coal," Journal of Law and Economics, XXXI, 47-83.

(1990): "The Performance of Long-Term Contracts: Further Evidence from Coal Markets," RAND Journal of Economics, 21, 251-274.

- (2003): "The Difficult Transition to Competitive Electricity Markets in the U.S." in Electricity Restructuring: Choices and Challenges, ed. by J. Griffen and S. Puller, University of Chicago Press.

Kerkvliet, J. And J. Shogren (1992): "The Impacts of Environmental Regulation on Coal Procurement Strategies: Design Coal and Multi-Attributed Quality," Journal of Environmental Management, 35, 83-91.

(2001): "The Determinants of Coal Contract Duration for the Powder River Basin," Journal of Instituional and Theoretical Economics, 157, 608-622.

Kozhevnikova, M. And I. Lange (2009): "Determinants of Contract Duration: Further Evidence from Coal-Fired Power Plants," Review of Industrial Organization, 34, 217-229.

Laffont, J. And M. S. Matoussi (1995): "Moral Hazard, Financial Constraints and Sharecropping in El Oulja," Review of Economic Studies, 62, 381-399.

Laffont, J. And J. Tirole (1993): A Theory of Incentives in Procurement and Regulation, MIT Press.

Lafontaine, F. (1991): "Agency Theory and Franchising: Some Empirical Results," RAND Journal of Economics, 23, 263-283.

Leffler, K. B. And R. R. Rucker (1991): "Transactions Costs and the Efficient Organization of Production: A Study of Timber-Harvesting Contracts," Journal of Political Economy, 99, 1060-87.

Liu, M., F. Wu, AND Y. Ni (2006): "A Survey on Risk Management in Electricity Markets," in Power Engineering Society General Meeting, IEEE. 
Malik, K., M. L. Cropper, A. Limonov, And A. Singh (2011): "Estimating the Impact of Restructuring on Electricity Generation Efficiency: The Case of the Indian Thermal Power Sector," NBER Working Papers 17383, National Bureau of Economic Research.

Mansur, E. T. (2007): "Upstream Competition and Vertical Integration in Electricity Markets," Journal of Law and Economics, 50, 125-156.

Markowitz, H. M. (1952): "Portfolio Selection," Journal of Finance, 7, 77-91.

— (1991): "Foundations of Portfolio Theory," Journal of Finance, 46, 469-477.

Martin, R. E. (1988): "Franchising and Risk Management," American Economic Review, $78,954-968$.

McAfee, R. P. And J. McMillan (1986): "Bidding for Contracts: A Principal-Agent Analysis," RAND Journal of Economics, 17, 326-338.

McDermott, K. (2012): "Cost of Service Regulation in the Investor-Owned Electric Utility Industry," Tech. rep., Edision Electric Institute.

Milgrom, P. And C. Shannon (1994): "Monotone Comparative Statics," Econometrica, 62 , pp. $157-180$.

Newbery, D. M. And M. G. Pollitt (1997): "The Restructuring and Privatization of Britain's CEGB - Was It Worth It?" Journal of Industrial Economics, 45, 269-303.

NG, C. K. And P. Seabright (2001): "Competition, Privatisation and Productive Efficiency: Evidence from the Airline Industry," Economic Journal, 111, 591-619.

Olley, S. And A. PAKes (1996): "The Dynamics of Productivity in the Telecommunications Equipment Industry," Econometrica, 64, 1263-1297.

Rockafellar, R. T. and S. P. Uryasev (2000): "Optimization of Conditional Value-atRisk," Journal of Risk, 2, 21-42.

Rubin, D. B. (1980): "Randomization Analysis of Experimental Data: The Fisher Randomization Test - Comment," Journal of the American Statistical Association, 75, 591-593.

Sandmo, A. (1971): "On the Theory of the Competitive Firm under Price Uncertainty," American Economic Review, 61, 65-73.

Slade, M. E. (1996): "Multitask Agency and Contract Choice: An Empirical Exploration," International Economic Review, 37, 465-486.

Syverson, C. (2004): "Market Structure and Productivity: A Concrete Example," Journal of Political Economy, 112, 1181-1222.

Tadelis, S. and O. E. Williamson (2012): "Transaction Cost Economics," in The Handbook of Organizational Economics, ed. by R. Gibbons and J. Roberts, Princeton, NJ: Princeton University Press, chap. 4.

U.S. EIA (2010): “Annual Energy Review," United States Energy Information Administration. 
Williamson, O. E. (1985): The Economic Institutions of Capitalism, New York: Free Press.

Wolfram, C. D. (1999): "Measuring Duopoly Power in the British Electricity Spot Market," American Economic Review, 89, 805-826.

YAmai, Y. AND T. Yoshiba (2005): "Value-at-risk versus expected shortfall: A practical perspective," Journal of Banking \& Finance, 29, 997-1015.

Yu, N., A. Somani, And L. Tesfatsion (2010): "Financial Risk Management in Restructured Wholesale Power Markets: Concepts and Tools," in Power and Energy Society General Meeting, IEEE.

Zhang, F. (2007): "Does Electricity Restructuring Work? Evidence from The U.S. Nuclear Energy Industry," The Journal of Industrial Economics, 55, 397-418.

\section{A Proof of Lemma 1}

Consider a fixed contract $\gamma=(r, d)$. Substituting the expression (1) for the price of coal into the value function of the mine given in (5), we obtain the mine's maximization problem:

$$
\max _{e \geq 0}\left(1+\theta^{m}\right)\left[\delta(r)+(1-r) \mathbb{E}(x(\chi, e))-\mathbb{E}(x(\chi, e))-k^{m}(r, d ; \mathbf{A})-g(e)\right]-\theta^{m} b(\alpha) r \sigma_{x},
$$

Differentiating the objective function with respect to $e$ we obtain that at the optimal level, $e^{*}$, we have

$$
F\left(e^{*}, r\right)=\left(1+\theta^{m}\right)\left[-r \frac{\partial \mathbb{E}\left(x\left(\chi, e^{*}\right)\right)}{\partial e}-\frac{\partial g\left(e^{*}\right)}{\partial e}\right]-\theta^{m} b(\alpha) r \frac{\partial \sigma_{x}}{\partial e}=0
$$

Recall that by assumption $\partial \mathbb{E}(x(\chi, e)) / \partial e<0, \partial g(e) / \partial e>0$ and $\partial \sigma_{x} / \partial e$ can be either positive, negative, or zero, thus an interior solution for $e^{*}$ is possible.

To verify that at $e^{*}$, we obtain a maximum, we study the second order condition:

$$
\frac{\partial^{2} V^{m}(\gamma, e)}{\partial e^{2}}=\left(1+\theta^{m}\right)\left[-r \frac{\partial^{2} \mathbb{E}\left(x\left(\chi, e^{*}\right)\right)}{\partial e^{2}}-\frac{\partial^{2} g\left(e^{*}\right)}{\partial e^{2}}\right]-\theta^{m} b(\alpha) r \frac{\partial^{2} \sigma_{x}}{\partial e^{2}}<0,
$$

where the last inequality follows from the assumptions that $\partial^{2} \mathbb{E}(x(\chi, e)) / \partial e^{2}>0, \partial^{2} g(e) / \partial e^{2}>$ 0 and $\partial^{2} \sigma_{x} / \partial e^{2} \geq 0$.

The monotonicity of $e^{*}$ with respect to $r$ can be established by using the implicit function theorem. From equation (A.1), we get,

$$
\frac{\partial e^{*}}{\partial r}=-\frac{\frac{\partial F\left(e^{*}, r\right)}{\partial r}}{\frac{\partial F\left(e^{*}, r\right)}{\partial e}}=-\frac{\left(1+\theta^{m}\right)\left(-\frac{\partial \mathbb{E}\left(x\left(\chi, e^{*}\right)\right)}{\partial e}\right)-\theta^{m} b(\alpha) \frac{\partial \sigma_{x}}{\partial e}}{\left(1+\theta^{m}\right)\left[-r \frac{\partial^{2} \mathbb{E}\left(x\left(\chi, e^{*}\right)\right)}{\partial e^{2}}-\frac{\partial^{2} g\left(e^{*}\right)}{\partial e^{2}}\right]-\theta^{m} b(\alpha) r \frac{\partial^{2} \sigma_{x}}{\partial e^{2}}} ;
$$

whose denominator is always negative as shown above and that the sign of the numerator does not depend on $r$ proving the claim. 
The direction of the monotonicity depends on the sign of the numerator of (A.2) . Clearly, if the numerator is positive, then $e^{*}$ increases with $r$. This is the case only when

$$
\left(1+\theta^{m}\right) \frac{\partial \mathbb{E}\left(x\left(\chi, e^{*}\right)\right)}{\partial e}+\theta^{m} b(\alpha) \frac{\partial \sigma_{x}}{\partial e}<0,
$$

which confirms the statement of part ii. of Lemma 1.

\section{B Proof of Proposition 1}

The optimal contract choice is given by the solution to the following problem:

$$
\begin{array}{cl}
\max _{r, d} & \left(1+\theta^{g}\right)\left\{\lambda\left[\mathbb{E}\left(p^{e}\right)-\bar{\delta}-\mu\right]+\mu-k^{g}(r, d ; \mathbf{A})\right\}-\theta^{g} b(\alpha) \lambda \sqrt{\sigma_{e}^{2}+(1-r)^{2} \sigma_{x}^{2}}, \\
\text { s.t. } & \left(1+\theta^{m}\right)\left[\bar{\delta}-\mathbb{E}\left(x\left(\chi, e^{*}(r)\right)-k^{m}(r, d ; \mathbf{A})-g\left(e^{*}(r)\right)\right]-\theta^{m} b(\alpha) r \sigma_{x} \geq 0 .\right.
\end{array}
$$

The associated Lagrangian is

$$
\begin{aligned}
\mathcal{L}=\left(1+\theta^{g}\right)\left\{\lambda\left[\mathbb{E}\left(p^{e}\right)-\bar{\delta}-\mu\right]+\mu-k^{g}(r, d ; \mathbf{A})\right\}-\theta^{g} b(\alpha) \lambda \sqrt{\sigma_{e}^{2}+(1-r)^{2} \sigma_{x}^{2}}+ \\
+\eta\left\{\left(1+\theta^{m}\right)\left[\bar{\delta}-\mathbb{E}\left(x\left(\chi, e^{*}(r)\right)-k^{m}(r, d ; \mathbf{A})-g\left(e^{*}(r)\right)\right]-\theta^{m} b(\alpha) r \sigma_{x}\right\}\right.
\end{aligned}
$$

and the necessary first-order conditions for a maximum are:

$$
\begin{aligned}
\frac{\partial \mathcal{L}}{\partial r}= & -\left(1+\theta^{g}\right) \frac{\partial k^{g}}{\partial r}+\theta^{g} b(\alpha) \lambda\left[\sigma_{e}^{2}+(1-r)^{2} \sigma_{x}^{2}\right]^{-1 / 2}(1-r) \sigma_{x}^{2}- \\
& -\eta\left(1+\theta^{m}\right)\left[\frac{\partial k^{m}}{\partial r}-\frac{\partial \mathbb{E}\left(x\left(\chi, e^{*}(r)\right)\right)}{\partial e} \frac{\partial e^{*}}{\partial r}-\frac{\partial g}{\partial e} \frac{\partial e^{*}}{\partial r}\right]-\eta \theta^{m} b(\alpha) \sigma_{x}=0,
\end{aligned}
$$

and

$$
\frac{\partial \mathcal{L}}{\partial d}=-\left(1+\theta^{g}\right) \frac{\partial k^{g}}{\partial d}-\eta\left(1+\theta^{m}\right) \frac{\partial k^{m}}{\partial d}=0
$$

Well know results in monotone comparative statics (see Milgrom and Shannon, 1994, theorem 5 ) assert that if $\mathcal{L}$ is supermodular in $(r,-d)$ and exhibits increasing returns in $(r,-d, \lambda)$, then the solutions to the maximization problem $r(\lambda)$, and $d(\lambda)$ are monotone non-decreasing and non-increasing, respectively.

To show that our objective function, $\mathcal{L}$, is supermodular in $(r,-d)$ and exhibits increasing differences in $(r,-d, \lambda)$ it suffices to show that the cross derivatives with respect to these three variables are non-negative (Milgrom and Shannon, 1994, theorem 6). Differentiating (B.2) with respect to $-d$ yields

$$
\frac{\partial^{2} \mathcal{L}}{\partial r \partial(-d)}=\left(1+\theta^{g}\right) \frac{\partial^{2} k^{g}}{\partial r \partial(d)}+\eta\left(1+\theta^{m}\right) \frac{\partial k^{m}}{\partial r \partial(d)}>0,
$$

where the last inequality follows from the properties of $k^{g}(r, d)$, and the positivity of $\eta$. Differentiation of (B.2) and (B.3) with respect to $\lambda$ yields

$$
\frac{\partial^{2} \mathcal{L}}{\partial r \partial \lambda}=\theta^{g} b(\alpha)(1-r) \sigma_{x}^{2}\left[\sigma_{e}^{2}+(1-r)^{2} \sigma_{x}^{2}\right]^{-1 / 2}>0, \quad \text { and } \quad \frac{\partial^{2} \mathcal{L}}{\partial(-d) \partial \lambda}=0
$$


respectively, which concludes our proof.

\section{Proof of Proposition 2}

The previous proof establishes that $\mathcal{L}$ is supermodular in $(r,-d)$. Differentiating the first-order conditions (B.2) and (B.3) with respect to $-A_{i}$, and $-\sigma_{e}^{2}$ one gets

$$
\begin{gathered}
\frac{\partial^{2} \mathcal{L}}{\partial r \partial\left(-\sigma_{e}\right)}=\theta^{g} b(\alpha) \lambda(1-r) \sigma_{x}^{2}\left[\sigma_{e}^{2}+(1-r)^{2} \sigma_{x}^{2}\right]^{-3 / 2} \sigma_{e}>0, \quad \text { and } \quad \frac{\partial^{2} \mathcal{L}}{\partial(-d) \partial\left(-\sigma_{e}\right)}=0 ; \\
\frac{\partial^{2} \mathcal{L}}{\partial r \partial\left(-A_{i}\right)}=0, \quad \text { and } \quad \frac{\partial^{2} \mathcal{L}}{\partial(-d) \partial\left(-A_{i}\right)}=-\left(1+\theta^{g}\right) \frac{\partial^{2} k^{g}}{\partial(-d) \partial\left(-A_{i}\right)}-\eta\left(1+\theta^{m}\right) \frac{\partial k^{m}}{\partial(-d) \partial\left(-A_{i}\right)}>0 ;
\end{gathered}
$$

that immediately establish that $\mathcal{L}$ exhibits increasing differences in $\left(r,-d,-\sigma_{e}^{2},-A_{i}\right)$, implying that $r^{*}$ is non-increasing in $\sigma_{e}$, and $A_{i}$, while $d^{*}$ is non-decreasing in both.

Finally, differentiating (B.2) and (B.3) with respect to $\sigma_{\chi}$ yields

$$
\frac{\partial^{2} \mathcal{L}}{\partial r \partial \sigma_{x}}=\theta^{g} b(\alpha) \lambda(1-r) \sigma_{x}\left[\sigma_{e}^{2}+(1-r)^{2} \sigma_{x}^{2}\right]^{-1 / 2}\left\{2-(1-r)^{2} \sigma_{x}^{2}\left[\sigma_{e}^{2}+(1-r)^{2} \sigma_{x}^{2}\right]^{-1}\right\}-\eta \theta^{m} b(\alpha),
$$

and,

$$
\frac{\partial^{2} \mathcal{L}}{\partial(-d) \partial \sigma_{x}}=0
$$

where it is apparent that it is not possible to sign in general the first cross derivative. This completes our proof. 
Figure 1: Average contract rigidity of treatment group relative to control (1991-2001).

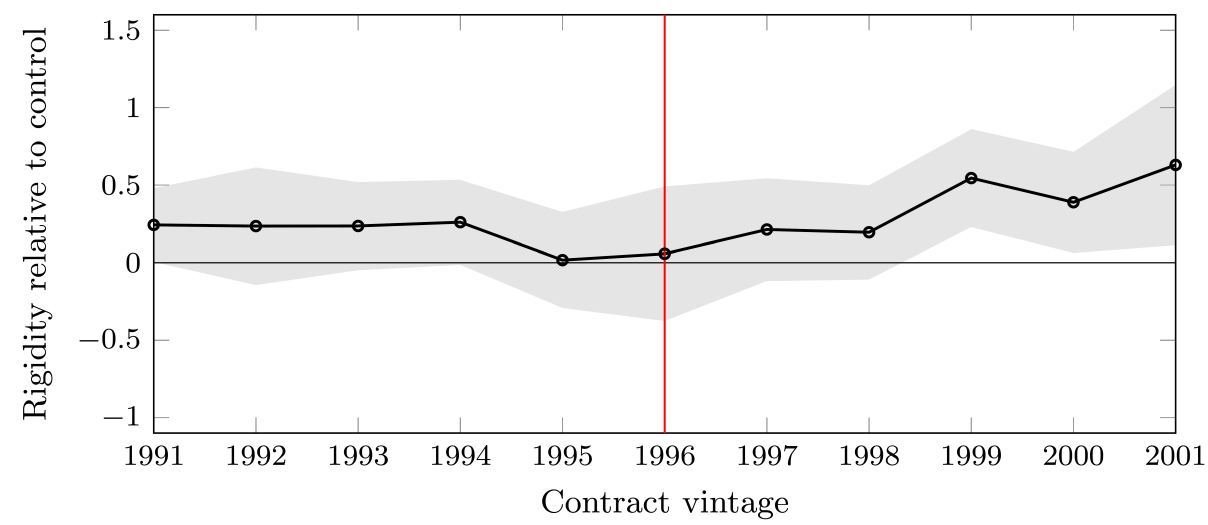

This figure shows the year-by-year estimated coefficient and the $90 \%$ confidence interval for rigidity of the price adjustment mechanism in treated contracts relative to control, before and after the treatment. Contracts are included in the treatment group if they are a new contract signed with a plant in a state which has passed restructuring legislation. The estimating equation is based on Equation (10). Standard errors are clustered at the level of the state the plant is located in. The vertical line indicates the first year that a state passed restructuring legislation.

Figure 2: Average contract duration of treatment group relative to control (1991-2001).

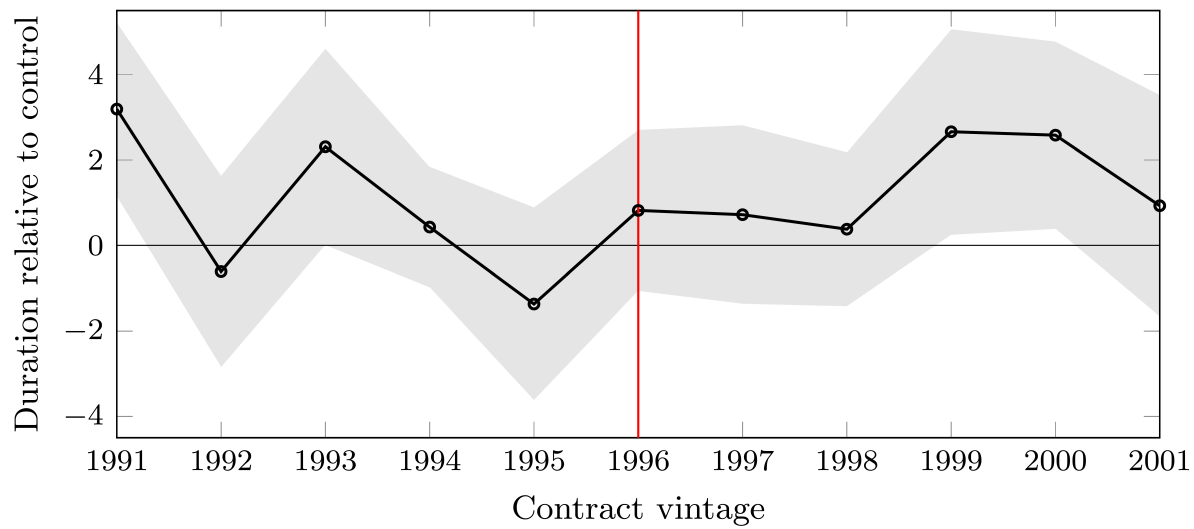

This figure shows the year-by-year estimated coefficient and the $90 \%$ confidence interval for duration in treated contracts relative to control, before and after the treatment. Contracts are included in the treatment group if they are a new contract signed with a plant in a state which has passed restructuring legislation. The estimating equation is based on Equation (11). Standard errors are clustered at the level of the state the plant is located in. The vertical line indicates the first year that a state passed restructuring legislation. 
Figure 3: Average contract rigidity for control group (1990-2001).

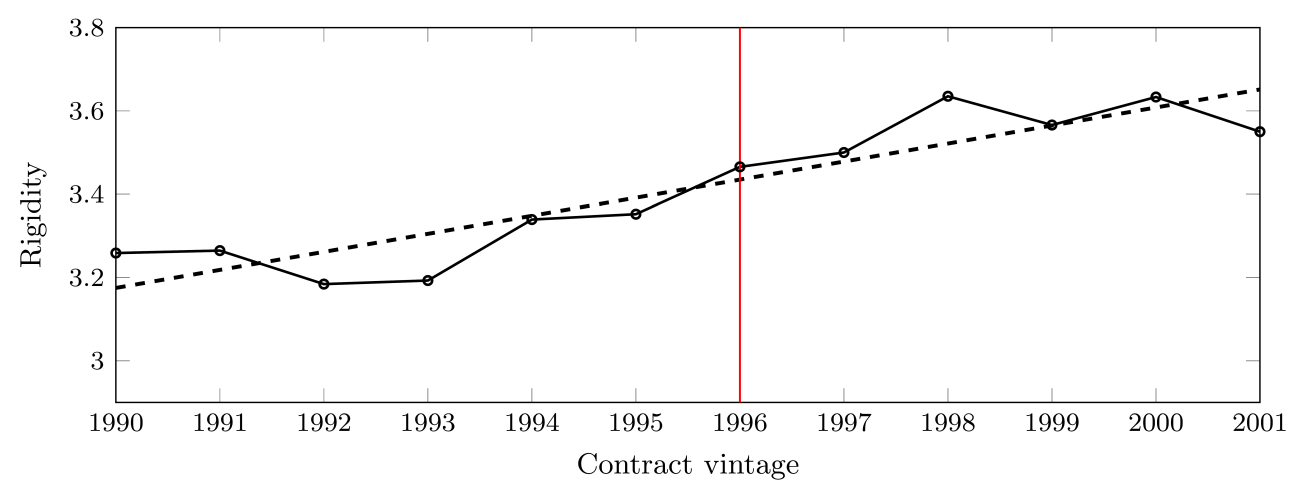

This figure shows the average yearly contractual rigidity for contracts in the control group, i.e. contracts signed by plants operating in states that have not passed restructuring legislation. The dashed line is the estimated trend over the entire period. The vertical line indicates the first year that a state passed restructuring legislation.

Figure 4: Average contract duration for control group (1990-2001).

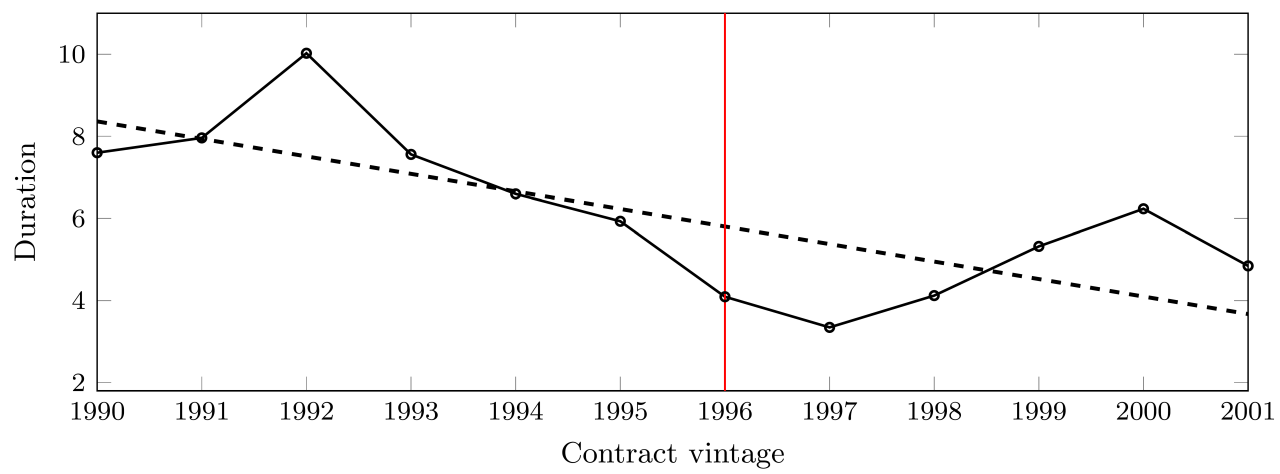

This figure shows the average yearly contractual duration in years for contracts in the control group, i.e. contracts signed by plants operating in states that have not passed restructuring legislation. The dashed line is the estimated trend over the entire period. The vertical line indicates the first year that a state passed restructuring legislation. 
Figure 5: Average contract rigidity of treatment group relative to control.

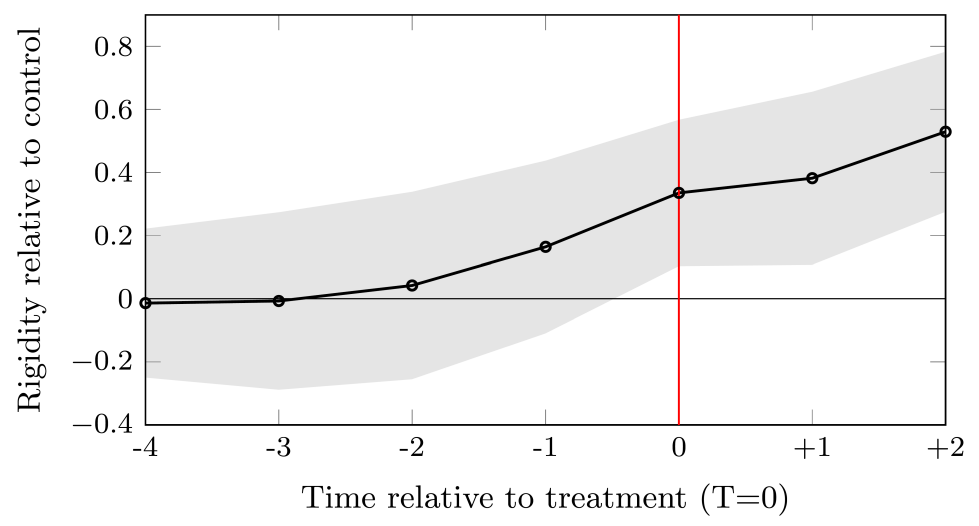

This figure shows the year-by-year estimated coefficient and the $90 \%$ confidence interval for duration in treated contracts relative to control, before and after the treatment. Time is normalized relative to the year that the state the plant is located in has passed restructuring legislation. Contracts are included in the treatment group if they are a new contract signed with a plant in a state which has passed restructuring legislation. The estimating equation is based on Equation (10). Standard errors are clustered at the level of the state the plant is located in. The vertical line indicates the first year that a state passed restructuring legislation.

Figure 6: Results of the placebo test - 10,000 iterations.

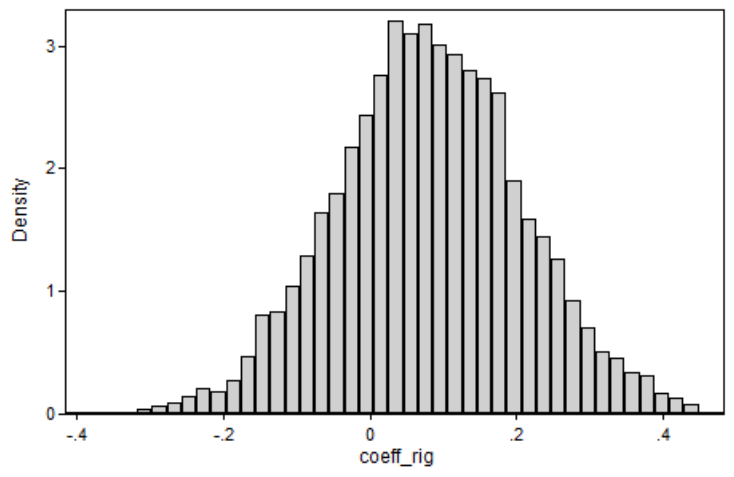

(a) Rigidity

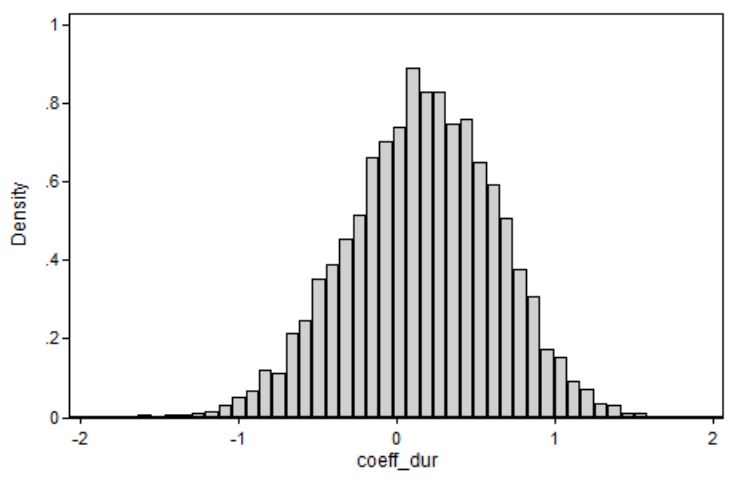

(b) Duration

This figure reports the results of the Placebo test conducted assigning at each iteration half of the plants located in regulated states to the placebo group. This procedure was repeated 10,000 times. The figure shows the distribution of the estimated coefficients of the placebo indicator obtained from a regression of contractual rigidity, panel (a), and duration, panel (b). The estimated equations replicate the instrumentation carried out in Table 4, Column (3), and Table 5, Column (3), respectively. 
Figure 7: Average labour productivity of treatment group relative to control (1991-2001).

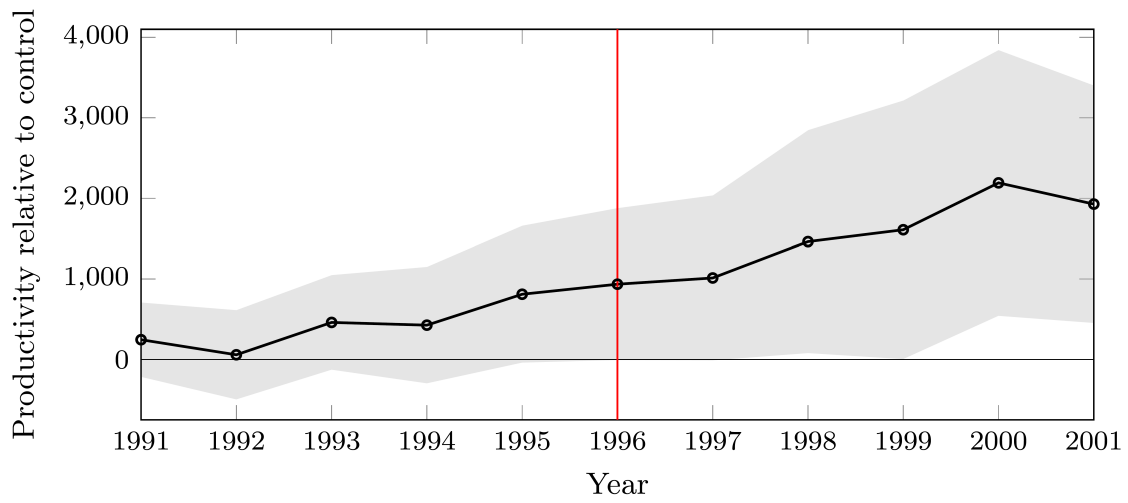

This figure shows the year-by-year estimated coefficient and the $90 \%$ confidence interval of labor productivity (in million tons per employee), for treated counties relative to control, before and after the treatment. Counties are included in the treatment group if at least one mine in the county has signed a new contract with a plant in a state which has passed restructuring legislation. The estimating equation is based on Equation (12). Standard errors are clustered at the state-county level. The vertical line indicates the first year that a state passed restructuring legislation.

Figure 8: Average productivity for control group (1990-2001).

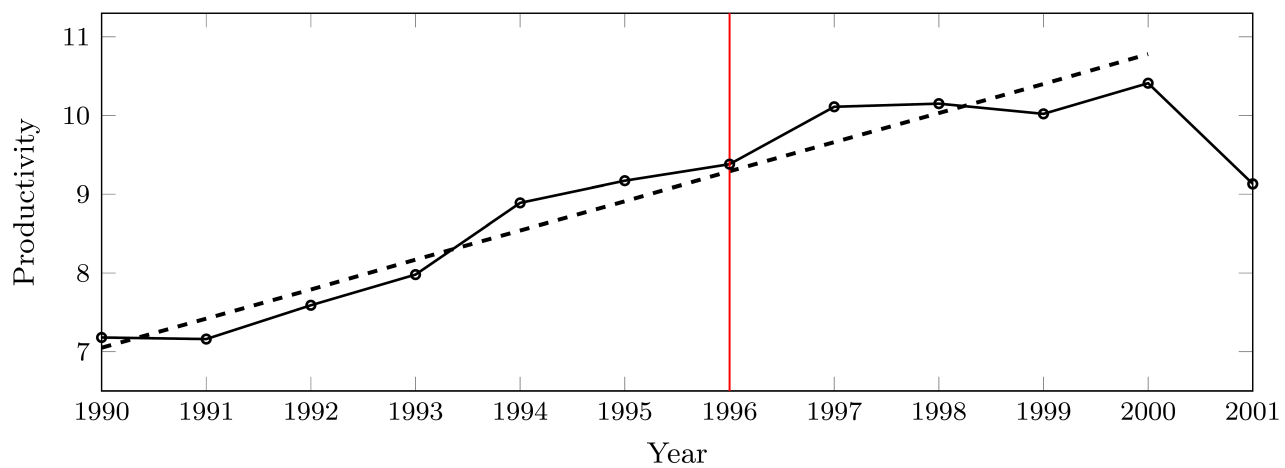

This figure shows the average yearly labour productivity for mines (counties) in the control group, i.e. for counties from which no coal was shipped to any of the restructured states. The dashed line is the estimated trend over 1990-2000. The vertical line indicates the first year that a state passed restructuring legislation. Coal productivity dropped across the industry in 2001 as documented in U.S. EIA (2010). 
Table 1: Description of Pricing Mechanisms

\begin{tabular}{|c|c|}
\hline Ordinal Designation & Description \\
\hline 4, Most Rigid & Fixed-Price Contract. Price is fixed over the life of the contract. \\
\hline 3 & $\begin{array}{l}\text { Base Price Plus Escalation. Different components of the price escalate } \\
\text { (or de-escalate) as a function of changing economic conditions (indices). }\end{array}$ \\
\hline 2 & $\begin{array}{l}\text { Price Tied to Market. Price tied to the price of coal being sold in a } \\
\text { particular market. Product and market area are defined in the contract. } \\
\text { Contract may contain a "Most Favored Nations" clause, i.e., supplier } \\
\text { will not sell to any generator at a price lower than yours is paying. }\end{array}$ \\
\hline 2 & $\begin{array}{l}\text { Cost-Plus Contract with a Fixed Fee Provision. Purchaser agrees to } \\
\text { pay all producer's costs plus a management fee. Some contracts } \\
\text { provide for payment of both a management fee and a profit. This } \\
\text { contract has a Fixed Fee provision. }\end{array}$ \\
\hline 2 & $\begin{array}{l}\text { Cost-Plus Contract with an Incentive Fee. Provision Purchaser agrees } \\
\text { to pay all producer's costs plus a management fee. Some contracts } \\
\text { provide for payment of both a management fee and a profit. This } \\
\text { contract has an Incentive Fee provision, i.e., a variable fee that is tied } \\
\text { to various productivity and cost reduction incentives. }\end{array}$ \\
\hline 1, Least Rigid & $\begin{array}{l}\text { Price Renegotiation. The price is renegotiated at predetermined } \\
\text { intervals, usually one year. This type of contract, frequently known as } \\
\text { an Evergreen Contract, may also contain provisions for price } \\
\text { adjustments between renegotiations. }\end{array}$ \\
\hline
\end{tabular}

Source: Federal Energy Regulatory Commission 
Table 2: Status of Electricity Restructuring

\begin{tabular}{|c|c|c|}
\hline State & Hearing Held & Law Passed \\
\hline Alabama & 1997 & \\
\hline Alaska & 1998 & \\
\hline Arizona & 1995 & 1998 \\
\hline Arkansas & 1997 & 1999 \\
\hline California & 1994 & 1996 \\
\hline Colorado & 1998 & \\
\hline Connecticut & 1994 & 1998 \\
\hline Delaware & 1995 & 1999 \\
\hline District of Columbia & 1996 & 2000 \\
\hline Florida & 2000 & \\
\hline Georgia & 1998 & \\
\hline Idaho & 1997 & \\
\hline Illinois & 1995 & 1997 \\
\hline Indiana & 1995 & \\
\hline Iowa & 1996 & \\
\hline Kansas & 1996 & \\
\hline Kentucky & 1996 & 1999 \\
\hline Louisiana & 1997 & \\
\hline Maine & 1995 & 1997 \\
\hline Maryland & 1995 & 1999 \\
\hline Massachusetts & 1994 & 1997 \\
\hline Michigan & 1994 & 2000 \\
\hline Minnesota & 1997 & \\
\hline Mississippi & 1997 & \\
\hline Missouri & 1997 & \\
\hline Montana & 1996 & 1997 \\
\hline Nebraska & 1996 & \\
\hline Nevada & 1994 & 1996 \\
\hline New Hampshire & 1994 & 1996 \\
\hline New Jersey & 1996 & 1999 \\
\hline New Mexico & 1995 & 1999 \\
\hline New York & 1993 & 1996 \\
\hline North Carolina & 1998 & \\
\hline North Dakota & 1997 & \\
\hline Ohio & 1996 & 1999 \\
\hline Oklahoma & 1995 & 1997 \\
\hline Oregon & 1995 & 1999 \\
\hline Pennsylvania & 1994 & 1996 \\
\hline Rhode Island & 1994 & 1996 \\
\hline South Carolina & 1997 & \\
\hline South Dakota & 1998 & \\
\hline Tennessee & 1997 & \\
\hline Texas & 1997 & 1999 \\
\hline Utah & 1997 & \\
\hline Vermont & 1995 & \\
\hline Virginia & 1995 & 1999 \\
\hline Washington & 1995 & \\
\hline West Virginia & 1995 & 1999 \\
\hline Wisconsin & 1997 & \\
\hline Wyoming & 1997 & \\
\hline
\end{tabular}

Source: U.S. Energy Information Administration 
Table 3: Summary Statistics

\begin{tabular}{|c|c|c|c|c|c|c|c|}
\hline & & (A) & (B) & (C) & (D) & & \\
\hline & All Data & $\begin{array}{c}\text { Control } \\
\text { before } 1996\end{array}$ & $\begin{array}{c}\text { Treated before } \\
\text { treatment }\end{array}$ & $\begin{array}{c}\text { Control } \\
\text { after } 1996\end{array}$ & $\begin{array}{c}\text { Treated after } \\
\text { treatment }\end{array}$ & $(\mathrm{A})-(\mathrm{B})$ & $(A)-(C)$ \\
\hline Rigidity & $\begin{array}{c}3.33 \\
(0.79)\end{array}$ & $\begin{array}{c}3.42 \\
(0.69)\end{array}$ & $\begin{array}{c}3.02 \\
(0.87)\end{array}$ & $\begin{array}{c}3.66 \\
(0.63)\end{array}$ & $\begin{array}{c}3.49 \\
(0.63)\end{array}$ & $\begin{array}{c}7.34 \\
(0.00)\end{array}$ & $\begin{array}{l}-4.27 \\
(0.00)\end{array}$ \\
\hline Duration & $\begin{array}{c}3.55 \\
(4.45)\end{array}$ & $\begin{array}{c}4.64 \\
(5.68)\end{array}$ & $\begin{array}{c}3.66 \\
(4.42)\end{array}$ & $\begin{array}{c}2.42 \\
(2.60)\end{array}$ & $\begin{array}{c}2.17 \\
(1.49)\end{array}$ & $\begin{array}{l}1.13 \\
(0.26)\end{array}$ & $\begin{array}{c}6.11 \\
(0.00)\end{array}$ \\
\hline Post $\mathrm{SO}_{2}$ Regulation & $\begin{array}{c}0.65 \\
(0.48)\end{array}$ & $\begin{array}{c}0.55 \\
(0.50)\end{array}$ & $\begin{array}{c}0.58 \\
(0.49)\end{array}$ & $\begin{array}{c}0.86 \\
(0.35)\end{array}$ & $\begin{array}{c}0.80 \\
(0.41)\end{array}$ & $\begin{array}{c}2.47 \\
(0.01)\end{array}$ & $\begin{array}{l}-8.33 \\
(0.00)\end{array}$ \\
\hline Post Restructuring & $\begin{array}{c}0.11 \\
(0.37)\end{array}$ & $\begin{array}{c}0.00 \\
(0.00)\end{array}$ & $\begin{array}{c}0.00 \\
(0.00)\end{array}$ & $\begin{array}{c}0.00 \\
(0.00)\end{array}$ & $\begin{array}{c}1.23 \\
(0.42)\end{array}$ & $\begin{array}{l}- \\
-\end{array}$ & $\begin{array}{l}- \\
-\end{array}$ \\
\hline Plant in Restructured State & $\begin{array}{c}0.46 \\
(0.50)\end{array}$ & $\begin{array}{c}0.00 \\
(0.00)\end{array}$ & $\begin{array}{l}1.00 \\
(0.00)\end{array}$ & $\begin{array}{c}0.00 \\
(0.00)\end{array}$ & $\begin{array}{l}1.00 \\
(0.00)\end{array}$ & $\begin{array}{l}- \\
-\end{array}$ & $\begin{array}{l}- \\
-\end{array}$ \\
\hline Previous Interaction & $\begin{array}{c}0.63 \\
(0.48)\end{array}$ & $\begin{array}{c}0.64 \\
(0.48)\end{array}$ & $\begin{array}{c}0.61 \\
(0.49)\end{array}$ & $\begin{array}{c}0.60 \\
(0.49)\end{array}$ & $\begin{array}{c}0.73 \\
(0.45)\end{array}$ & $\begin{array}{c}0.91 \\
(0.36)\end{array}$ & $\begin{array}{c}0.83 \\
(0.41)\end{array}$ \\
\hline$Z$-Ash & $\begin{array}{l}-0.04 \\
(0.92)\end{array}$ & $\begin{array}{c}0.04 \\
(1.01)\end{array}$ & $\begin{array}{l}-0.10 \\
(0.88)\end{array}$ & $\begin{array}{l}-0.03 \\
(0.89)\end{array}$ & $\begin{array}{l}-0.08 \\
(0.85)\end{array}$ & $\begin{array}{c}2.17 \\
(0.03)\end{array}$ & $\begin{array}{c}0.87 \\
(0.39)\end{array}$ \\
\hline$Z$-Sulfur & $\begin{array}{c}0.19 \\
(1.04)\end{array}$ & $\begin{array}{c}0.12 \\
(1.05)\end{array}$ & $\begin{array}{c}0.06 \\
(0.96)\end{array}$ & $\begin{array}{c}0.37 \\
(1.07)\end{array}$ & $\begin{array}{c}0.51 \\
(1.12)\end{array}$ & $\begin{array}{c}2.84 \\
(0.00)\end{array}$ & $\begin{array}{l}-2.70 \\
(0.01)\end{array}$ \\
\hline$Z$-Btu & $\begin{array}{c}0.13 \\
(0.60)\end{array}$ & $\begin{array}{c}0.09 \\
(0.50)\end{array}$ & $\begin{array}{c}0.21 \\
(0.59)\end{array}$ & $\begin{array}{c}0.02 \\
(0.76)\end{array}$ & $\begin{array}{c}0.18 \\
(0.50)\end{array}$ & $\begin{array}{l}-3.20 \\
(0.00)\end{array}$ & $\begin{array}{l}1.26 \\
(0.21)\end{array}$ \\
\hline Minimum Quantity & $\begin{array}{c}0.49 \\
(0.71)\end{array}$ & $\begin{array}{c}0.58 \\
(0.83)\end{array}$ & $\begin{array}{c}0.37 \\
(0.54)\end{array}$ & $\begin{array}{c}0.61 \\
(0.83)\end{array}$ & $\begin{array}{c}0.32 \\
(0.46)\end{array}$ & $\begin{array}{c}4.36 \\
(0.00)\end{array}$ & $\begin{array}{l}-0.54 \\
(0.59)\end{array}$ \\
\hline Appalachia Mine & $\begin{array}{c}0.58 \\
(0.49)\end{array}$ & $\begin{array}{c}0.30 \\
(0.46)\end{array}$ & $\begin{array}{c}0.82 \\
(0.38)\end{array}$ & $\begin{array}{c}0.46 \\
(0.50)\end{array}$ & $\begin{array}{c}0.83 \\
(0.38)\end{array}$ & $\begin{array}{l}-16.73 \\
(0.00)\end{array}$ & $\begin{array}{l}-3.82 \\
(0.00)\end{array}$ \\
\hline Interior Mine & $\begin{array}{c}0.15 \\
(0.36)\end{array}$ & $\begin{array}{c}0.33 \\
(0.47)\end{array}$ & $\begin{array}{c}0.03 \\
(0.17)\end{array}$ & $\begin{array}{c}0.17 \\
(0.37)\end{array}$ & $\begin{array}{c}0.05 \\
(0.21)\end{array}$ & $\begin{array}{l}11.01 \\
(0.00)\end{array}$ & $\begin{array}{c}4.61 \\
(0.00)\end{array}$ \\
\hline Western Mine & $\begin{array}{c}0.27 \\
(0.44)\end{array}$ & $\begin{array}{c}0.37 \\
(0.48)\end{array}$ & $\begin{array}{c}0.15 \\
(0.36)\end{array}$ & $\begin{array}{c}0.37 \\
(0.49)\end{array}$ & $\begin{array}{c}0.13 \\
(0.33)\end{array}$ & $\begin{array}{c}7.34 \\
(0.00)\end{array}$ & $\begin{array}{l}-0.17 \\
(0.87)\end{array}$ \\
\hline Mine Dedicated Assets & $\begin{array}{c}0.14 \\
(0.25)\end{array}$ & $\begin{array}{c}0.16 \\
(0.27)\end{array}$ & $\begin{array}{c}0.11 \\
(0.21)\end{array}$ & $\begin{array}{c}0.15 \\
(0.28)\end{array}$ & $\begin{array}{c}0.15 \\
(0.25)\end{array}$ & $\begin{array}{c}2.80 \\
(0.01)\end{array}$ & $\begin{array}{c}0.56 \\
(0.57)\end{array}$ \\
\hline Plant Dedicated Assets & $\begin{array}{c}0.19 \\
(0.25)\end{array}$ & $\begin{array}{c}0.22 \\
(0.27)\end{array}$ & $\begin{array}{c}0.18 \\
(0.23)\end{array}$ & $\begin{array}{c}0.20 \\
(0.26)\end{array}$ & $\begin{array}{c}0.15 \\
(0.22)\end{array}$ & $\begin{array}{c}3.17 \\
(0.00)\end{array}$ & $\begin{array}{c}0.67 \\
(0.50)\end{array}$ \\
\hline Mandatory Phase I Plant & $\begin{array}{c}0.32 \\
(0.47)\end{array}$ & $\begin{array}{c}0.39 \\
(0.49)\end{array}$ & $\begin{array}{c}0.25 \\
(0.43)\end{array}$ & $\begin{array}{c}0.29 \\
(0.45)\end{array}$ & $\begin{array}{c}0.42 \\
(0.50)\end{array}$ & $\begin{array}{c}2.26 \\
(0.02)\end{array}$ & $\begin{array}{c}2.48 \\
(0.01)\end{array}$ \\
\hline Log of Utilization Variability & $\begin{array}{c}8.15 \\
(1.42)\end{array}$ & $\begin{array}{c}7.33 \\
(1.36)\end{array}$ & $\begin{array}{c}8.82 \\
(1.13)\end{array}$ & $\begin{array}{c}7.70 \\
(1.29)\end{array}$ & $\begin{array}{c}9.38 \\
(0.59)\end{array}$ & $\begin{array}{r}-14.10 \\
(0.00)\end{array}$ & $\begin{array}{l}-3.27 \\
(0.00)\end{array}$ \\
\hline Time to First Renegotiation & $\begin{array}{c}3.34 \\
(3.14)\end{array}$ & $\begin{array}{c}3.57 \\
(3.52)\end{array}$ & $\begin{array}{c}3.66 \\
(3.31)\end{array}$ & $\begin{array}{c}2.87 \\
(2.49)\end{array}$ & $\begin{array}{c}2.46 \\
(2.00)\end{array}$ & $\begin{array}{l}-1.82 \\
(0.07)\end{array}$ & $\begin{array}{c}3.75 \\
(0.00)\end{array}$ \\
\hline Mine-mouth Plant & $\begin{array}{c}0.01 \\
(0.08)\end{array}$ & $\begin{array}{c}0.01 \\
(0.08)\end{array}$ & $\begin{array}{c}0.01 \\
(0.11)\end{array}$ & $\begin{array}{c}0.00 \\
(0.00)\end{array}$ & $\begin{array}{c}0.00 \\
(0.00)\end{array}$ & $\begin{array}{l}-1.35 \\
(0.18)\end{array}$ & $\begin{array}{c}2.00 \\
(0.05)\end{array}$ \\
\hline Log of Mine Productivity & $\begin{array}{c}8.80 \\
(0.86)\end{array}$ & $\begin{array}{c}8.67 \\
(0.75)\end{array}$ & $\begin{array}{c}8.67 \\
(0.92)\end{array}$ & $\begin{array}{c}8.89 \\
(0.88)\end{array}$ & $\begin{array}{c}9.00 \\
(0.86)\end{array}$ & $\begin{array}{c}0.10 \\
(0.92)\end{array}$ & $\begin{array}{l}-4.36 \\
(0.00)\end{array}$ \\
\hline Injuries Per Worker & $\begin{array}{c}0.07 \\
(0.10)\end{array}$ & $\begin{array}{c}0.07 \\
(0.07)\end{array}$ & $\begin{array}{c}0.07 \\
(0.06)\end{array}$ & $\begin{array}{c}0.06 \\
(0.11)\end{array}$ & $\begin{array}{c}0.07 \\
(0.15)\end{array}$ & $\begin{array}{l}-0.66 \\
(0.51)\end{array}$ & $\begin{array}{c}2.32 \\
(0.02)\end{array}$ \\
\hline Continuous Production & $\begin{array}{c}0.57 \\
(0.28)\end{array}$ & $\begin{array}{c}0.61 \\
(0.27)\end{array}$ & $\begin{array}{c}0.57 \\
(0.24)\end{array}$ & $\begin{array}{c}0.55 \\
(0.31)\end{array}$ & $\begin{array}{c}0.53 \\
(0.26)\end{array}$ & $\begin{array}{c}2.27 \\
(0.02)\end{array}$ & $\begin{array}{c}3.09 \\
(0.00)\end{array}$ \\
\hline Underground Mine & $\begin{array}{c}0.26 \\
(0.30)\end{array}$ & $\begin{array}{c}0.25 \\
(0.30)\end{array}$ & $\begin{array}{c}0.28 \\
(0.30)\end{array}$ & $\begin{array}{c}0.25 \\
(0.30)\end{array}$ & $\begin{array}{c}0.27 \\
(0.27)\end{array}$ & $\begin{array}{l}-1.65 \\
(0.10)\end{array}$ & $\begin{array}{c}0.14 \\
(0.89)\end{array}$ \\
\hline
\end{tabular}

Sample means and standard deviations (in parentheses).

See Sections 4.2, 5.1, and 5.2 for detailed descriptions of all data series, including sources. 
Table 4: Contract Choice - Rigidity

\begin{tabular}{|c|c|c|c|c|c|}
\hline & (1) & $(2)$ & $(3)$ & (4) & $(5)$ \\
\hline & Ordered Probit & IV-Oprobit & IV & End. Matching & 3SLS \\
\hline Duration & $\begin{array}{c}-0.09^{* * *} \\
(0.02)\end{array}$ & $\begin{array}{c}-0.09^{* * * *} \\
(0.02)\end{array}$ & $\begin{array}{l}-0.04^{*} \\
(0.02)\end{array}$ & $\begin{array}{c}-0.10^{* * *} \\
(0.02)\end{array}$ & $\begin{array}{c}-0.05^{* * *} \\
(0.01)\end{array}$ \\
\hline Post Restructuring & $\begin{array}{l}0.27^{*} \\
(0.15)\end{array}$ & $\begin{array}{l}0.27^{*} \\
(0.15)\end{array}$ & $\begin{array}{c}0.29^{* * *} \\
(0.06)\end{array}$ & $\begin{array}{c}0.34^{* *} \\
(0.15)\end{array}$ & $\begin{array}{c}0.20^{* * *} \\
(0.07)\end{array}$ \\
\hline Plant in Restructured State & $\begin{array}{c}-0.54^{* *} \\
(0.23)\end{array}$ & $\begin{array}{c}-0.54^{* *} \\
(0.23)\end{array}$ & $\begin{array}{c}-0.39^{* * *} \\
(0.12)\end{array}$ & $\begin{array}{c}-0.49^{* *} \\
(0.23)\end{array}$ & $\begin{array}{c}-0.35^{* * *} \\
(0.06)\end{array}$ \\
\hline Previous Interaction & $\begin{array}{c}0.10 \\
(0.09)\end{array}$ & $\begin{array}{c}0.10 \\
(0.09)\end{array}$ & $\begin{array}{c}0.01 \\
(0.04)\end{array}$ & $\begin{array}{c}0.11 \\
(0.09)\end{array}$ & $\begin{array}{l}-0.01 \\
(0.05)\end{array}$ \\
\hline Post $\mathrm{SO}_{2}$ Regulation & $\begin{array}{l}-0.09 \\
(0.10)\end{array}$ & $\begin{array}{l}-0.09 \\
(0.10)\end{array}$ & $\begin{array}{l}-0.03 \\
(0.06)\end{array}$ & $\begin{array}{l}-0.06 \\
(0.11)\end{array}$ & $\begin{array}{l}-0.03 \\
(0.06)\end{array}$ \\
\hline Mandatory Phase I Plant & $\begin{array}{c}0.33^{* * *} \\
(0.13)\end{array}$ & $\begin{array}{c}0.34^{* *} \\
(0.13)\end{array}$ & $\begin{array}{c}0.17^{* * *} \\
(0.07)\end{array}$ & $\begin{array}{c}0.28^{* *} \\
(0.14)\end{array}$ & $\begin{array}{c}0.22^{* * *} \\
(0.05)\end{array}$ \\
\hline$Z$-Ash & $\begin{array}{c}0.07 \\
(0.05)\end{array}$ & $\begin{array}{c}0.07 \\
(0.05)\end{array}$ & $\begin{array}{l}0.06^{* *} \\
(0.02)\end{array}$ & $\begin{array}{c}0.07 \\
(0.04)\end{array}$ & $\begin{array}{c}0.04 \\
(0.02)\end{array}$ \\
\hline$Z$-Sulfur & $\begin{array}{l}0.08^{*} \\
(0.04)\end{array}$ & $\begin{array}{l}0.08^{*} \\
(0.04)\end{array}$ & $\begin{array}{c}0.04 \\
(0.02)\end{array}$ & $\begin{array}{l}0.08^{*} \\
(0.04)\end{array}$ & $\begin{array}{c}0.05^{* * *} \\
(0.02)\end{array}$ \\
\hline$Z$-Btu & $\begin{array}{l}-0.23^{*} \\
(0.13)\end{array}$ & $\begin{array}{l}-0.23^{*} \\
(0.12)\end{array}$ & $\begin{array}{c}-0.14^{* *} \\
(0.06)\end{array}$ & $\begin{array}{c}-0.24^{* *} \\
(0.12)\end{array}$ & $\begin{array}{c}-0.12^{* * *} \\
(0.04)\end{array}$ \\
\hline Underground Mine & $\begin{array}{l}-0.32 \\
(0.21)\end{array}$ & $\begin{array}{l}-0.32 \\
(0.22)\end{array}$ & $\begin{array}{l}-0.17 \\
(0.11)\end{array}$ & $\begin{array}{l}-0.28 \\
(0.21)\end{array}$ & $\begin{array}{c}-0.19^{* *} \\
(0.09)\end{array}$ \\
\hline Interior Mine & $\begin{array}{c}0.34 \\
(0.26)\end{array}$ & $\begin{array}{c}0.34 \\
(0.26)\end{array}$ & $\begin{array}{c}0.22 \\
(0.14)\end{array}$ & $\begin{array}{c}0.31 \\
(0.26)\end{array}$ & $\begin{array}{l}0.15^{* *} \\
(0.06)\end{array}$ \\
\hline Western Mine & $\begin{array}{c}0.45^{* * *} \\
(0.17)\end{array}$ & $\begin{array}{c}0.44^{* * *} \\
(0.17)\end{array}$ & $\begin{array}{c}0.28^{* * *} \\
(0.09)\end{array}$ & $\begin{array}{c}0.44^{* * *} \\
(0.17)\end{array}$ & $\begin{array}{c}0.28^{* * *} \\
(0.06)\end{array}$ \\
\hline Log of Utilization Variability & $\begin{array}{c}0.01 \\
(0.08)\end{array}$ & $\begin{array}{c}0.01 \\
(0.08)\end{array}$ & $\begin{array}{c}0.05 \\
(0.04)\end{array}$ & $\begin{array}{l}-0.05 \\
(0.08)\end{array}$ & $\begin{array}{c}0.03 \\
(0.02)\end{array}$ \\
\hline Year Signed & $\begin{array}{c}0.05^{* * *} \\
(0.00)\end{array}$ & $\begin{array}{c}0.05^{* * *} \\
(0.00)\end{array}$ & $\begin{array}{c}0.02 \\
(0.01)\end{array}$ & $\begin{array}{c}0.02^{* * *} \\
(0.00)\end{array}$ & $\begin{array}{l}0.02^{*} \\
(0.01)\end{array}$ \\
\hline Constant & $\begin{array}{l}- \\
-\end{array}$ & $\begin{array}{l}- \\
-\end{array}$ & $\begin{array}{l}-32.27 \\
(29.61)\end{array}$ & $\begin{array}{l}- \\
-\end{array}$ & $\begin{array}{l}-33.65 \\
(21.23)\end{array}$ \\
\hline $\begin{array}{l}\text { Observations } \\
\text { R-squared }\end{array}$ & $\begin{array}{l}1051 \\
0.16\end{array}$ & $\begin{array}{c}1191 \\
-\end{array}$ & $\begin{array}{l}1022 \\
0.23\end{array}$ & $\begin{array}{c}1201 \\
-\end{array}$ & $\begin{array}{l}1022 \\
0.23\end{array}$ \\
\hline $\begin{array}{l}\text { Test for instruments' relevance } \\
p \text {-value }\end{array}$ & $\begin{array}{l}- \\
-\end{array}$ & $\begin{array}{c}51.99 \\
0.00\end{array}$ & $\begin{array}{c}12.51 \\
0.00\end{array}$ & $\begin{array}{c}51.19 \\
0.00\end{array}$ & $\begin{array}{c}172.67 \\
0.00\end{array}$ \\
\hline
\end{tabular}

Notes: *,**,*** indicate $10 \%, 5 \%$ and $1 \%$ statistical significance, respectively. Time period for all regressions is 1990-2001. (1)-(4): Standard errors corrected for State-level serial correlation in parentheses. In (2)-(5), the Instruments for Duration are: Mine Dedicated Assets, Plant Dedicated Assets, Minimum Quantity, and Multiple Mode of Delivery. In (3) and (5), Rigidity is treated as a continuous variable. In (3)Hansen's test fails to reject the null that the instruments are valid $(J$-test $=5.54, p$-value $=0.14)$, the model passes the Kleinbergen-Paap under-identification test $(L M$ statistic $=15.09, p$-value $=0.00)$; the Kleinbergen-Paap Wald test for weak identification is 10.64. In (4), the matching equation specifies the $\log$ of Utilization Variability as a function of Interior, Western Mine, and State dummies, as well as State dummies interactions with $Z$-Ash, $Z$-Sulfur, $Z$-Btu, and Underground Mine; the $F$-test for the matching equation is 54.94 ( $p$-value $=0.00)$, the adjusted $\mathrm{R}^{2}$ is 0.85 . 
Table 5: Contract Choice - Duration

\begin{tabular}{|c|c|c|c|c|}
\hline & $(1)$ & $(2)$ & $(3)$ & $(4)$ \\
\hline & OLS & IV & IV & 3SLS \\
\hline Rigidity & $\begin{array}{c}-1.10^{* * *} \\
(0.27)\end{array}$ & $\begin{array}{c}-2.55^{* * *} \\
(0.64)\end{array}$ & $\begin{array}{c}-3.45^{* * *} \\
(1.04)\end{array}$ & $\begin{array}{c}-2.42^{* * *} \\
(0.54)\end{array}$ \\
\hline Post Restructuring & $\begin{array}{c}0.45 \\
(0.39)\end{array}$ & $\begin{array}{l}0.70^{*} \\
(0.33)\end{array}$ & $\begin{array}{c}0.65 \\
(0.47)\end{array}$ & $\begin{array}{c}0.65 \\
(0.43)\end{array}$ \\
\hline Plant in Restructured State & $\begin{array}{l}-0.39 \\
(0.43)\end{array}$ & $\begin{array}{c}-1.25^{* * *} \\
(0.43)\end{array}$ & $\begin{array}{c}-1.33^{* *} \\
(0.59)\end{array}$ & $\begin{array}{c}-0.99 * * * \\
(0.35)\end{array}$ \\
\hline Previous Interaction & $\begin{array}{l}-0.06 \\
(0.19)\end{array}$ & $\begin{array}{l}-0.08 \\
(0.17)\end{array}$ & $\begin{array}{c}0.03 \\
(0.24)\end{array}$ & $\begin{array}{l}-0.02 \\
(0.24)\end{array}$ \\
\hline Post SO2 Regulation & $\begin{array}{c}12.27^{* * *} \\
(2.28)\end{array}$ & $\begin{array}{l}12.30^{* * *} \\
(2.20)\end{array}$ & $\begin{array}{c}10.78^{* * *} \\
(2.67)\end{array}$ & $\begin{array}{c}11.39 * * * \\
(1.08)\end{array}$ \\
\hline Mandatory Phase I Plant & $\begin{array}{c}0.73^{* *} \\
(0.36)\end{array}$ & $\begin{array}{c}0.84^{* * *} \\
(0.25)\end{array}$ & $\begin{array}{c}1.20^{* * *} \\
(0.34)\end{array}$ & $\begin{array}{c}0.98^{* * *} \\
(0.27)\end{array}$ \\
\hline Mine Dedicated Assets & $\begin{array}{l}0.99 * * \\
(0.39)\end{array}$ & $\begin{array}{c}0.96^{* * *} \\
(0.27)\end{array}$ & $\begin{array}{l}0.75^{*} \\
(0.44)\end{array}$ & $\begin{array}{c}0.96^{* *} \\
(0.43)\end{array}$ \\
\hline Plant Dedicated Assets & $\begin{array}{l}-0.81 \\
(0.58)\end{array}$ & $\begin{array}{l}-0.48 \\
(0.49)\end{array}$ & $\begin{array}{l}-0.65 \\
(0.59)\end{array}$ & $\begin{array}{l}-0.67 \\
(0.44)\end{array}$ \\
\hline Multiple Mode of Delivery & $\begin{array}{l}0.66^{*} \\
(0.35)\end{array}$ & $\begin{array}{c}0.69^{* *} \\
(0.30)\end{array}$ & $\begin{array}{c}0.92^{* *} \\
(0.39)\end{array}$ & $\begin{array}{c}0.29 \\
(0.23)\end{array}$ \\
\hline Minimum Quantity & $\begin{array}{c}2.20^{* * *} \\
(0.55)\end{array}$ & $\begin{array}{c}1.83^{* * *} \\
(0.43)\end{array}$ & $\begin{array}{c}2.11^{* * *} \\
(0.62)\end{array}$ & $\begin{array}{c}2.09^{* * *} \\
(0.18)\end{array}$ \\
\hline Constant & $\begin{array}{c}7.05^{* * *} \\
(1.17)\end{array}$ & $\begin{array}{c}11.87^{* * *} \\
(2.35)\end{array}$ & $\begin{array}{c}14.67^{* * *} \\
(3.67)\end{array}$ & $\begin{array}{c}11.57^{* * *} \\
(1.81)\end{array}$ \\
\hline Observations & 1048 & 1022 & 1034 & 1022 \\
\hline R-squared & 0.36 & 0.31 & 0.22 & 0.32 \\
\hline $\begin{array}{l}\text { Test for instruments' relevance } \\
p \text {-value }\end{array}$ & $\begin{array}{l}- \\
-\end{array}$ & $\begin{array}{l}4.34 \\
0.00\end{array}$ & $\begin{array}{c}12.00 \\
0.00\end{array}$ & $\begin{array}{c}24.63 \\
0.00\end{array}$ \\
\hline
\end{tabular}

Notes: $*, * *, * * *$ indicate $10 \%, 5 \%$ and $1 \%$ statistical significance, respectively. Time period for all regressions is 1990-2001. Vintage dummies are included in all regressions. (1)-(3): Standard errors corrected for State-level serial correlation in parentheses. In (2), the instruments for Rigidity are: $Z$-Ash, $Z$-Sulfur, $Z$-Btu, Underground Mine, Interior Mine, Western Mine, Log of Utilization Variability; in this model, Hansen's test fails to reject the null that the instruments are valid $(J$-test $=7.73, p$-value $=0.26)$, the model passes both the Kleinbergen-Paap under-identification test $(L M$ statistic $=12.17, p$-value $=0.08)$; the Cragg-Donald Wald test for weak identification is 12.86 . In (3), the only instrument for Rigidity is Western Mine; the model passes both the Kleinbergen-Paap under-identification test $(L M$ statistic $=8.55, p$-value $=0.00)$ and the Cragg-Donald Wald test for weak identification $(F$-test $=36.68)$. 
Table 6: Test of Stable Unit Treatment Value Assumption (SUTVA)

\begin{tabular}{lccc}
\hline \hline & $(1)$ & $(2)$ & $(3)$ \\
\cline { 2 - 4 } & Ordered Probit & IV-Oprobit & IV \\
\hline Duration & $-0.10^{* * * *}$ & $-0.02^{* * *}$ & $-0.08^{* *}$ \\
Mine Selling to Both Plant Types & $(0.01)$ & $(0.00)$ & $(0.01)$ \\
& 0.08 & -0.02 & -0.01 \\
Previous Interaction & $(0.15)$ & $(0.10)$ & $(0.05)$ \\
Post SO2 Regulation & $0.25^{*}$ & 0.08 & 0.09 \\
& $(0.14)$ & $(0.05)$ & $(0.07)$ \\
Mandatory Phase I Plant & -0.04 & -0.03 & 0.02 \\
Z-Ash & $(0.14)$ & $(0.06)$ & $(0.06)$ \\
Z-Sulfur & $0.205^{*}$ & 0.12 & 0.1 \\
Z-Btu & $(0.16)$ & $(0.12)$ & $(0.09)$ \\
Underground Mine & 0.08 & 0.03 & 0.02 \\
Interior Mine & $(0.06)$ & $(0.02)$ & $(0.03)$ \\
Western Mine & 0.05 & 0.01 & 0.01 \\
Log of Utilization Variability & $(0.05)$ & $(0.02)$ & $(0.02)$ \\
Year Signed & -0.15 & -0.04 & $-0.08^{* *}$ \\
Constant & $(0.09)$ & $(0.05)$ & $(0.04)$ \\
R-value & $-0.51^{* *}$ & -0.22 & $-0.25^{* *}$ \\
\hline \hline & $(0.25)$ & $(0.14)$ & $(0.12)$ \\
Observations & 0.30 & 0.09 & 0.01 \\
& $(0.24)$ & $(0.19)$ & $(0.12)$ \\
& - & $0.23^{* * *}$ & $0.15^{* *}$ \\
& $0.43^{* * *}$ & $(0.09)$ & $(0.06)$ \\
& $(0.14)$ & 0.01 & 0.04 \\
& 0.04 & $(0.06)$ & $(0.03)$ \\
& $(0.06)$ & $0.03^{* *}$ & 0.00 \\
& $0.05^{* * *}$ & $(0.01)$ & $(0.01)$ \\
& $(0.00)$ & $-57.89^{* *}$ & -6.22 \\
& - & $(24.38)$ & $(24.23)$ \\
\hline
\end{tabular}

Notes: $*, * *, * * *$ indicate $10 \%, 5 \%$ and $1 \%$ statistical significance, respectively. Time period for all regressions is 1990-2001. Standard errors corrected for State-level serial correlation in parentheses. In (2)-(3), the Instruments for Duration are: Mine Dedicated Assets, Plant Dedicated Assets, and Minimum Quantity. In (3), Rigidity is treated as a continuous variable, Duration as not truncated; in this model Hansen's test fails to reject the null that the instruments are valid $(J$-test $=0.42, p$-value $=0.81)$, the model passes both the Kleinbergen-Paap underidentification test $(L M$ statistic $=10.56, p$-value $=0.01)$ and the Cragg-Donald Wald test for weak identification $(F$-test=23.08). 
Table 7: Mine Productivity

\begin{tabular}{|c|c|}
\hline & Fixed Effects \\
\hline & Labour Productivity \\
\hline Coal to Restructured State & $\begin{array}{l}1050.91^{*} \\
(561.85)\end{array}$ \\
\hline Injuries per worker & $\begin{array}{c}2802.69 \\
(1958.89)\end{array}$ \\
\hline$(\text { Injuries per worker })^{2}$ & $\begin{array}{c}-1166.76^{*} \\
(613.93)\end{array}$ \\
\hline Continuous Production & $\begin{array}{c}10165.93^{* * *} \\
(1897.71)\end{array}$ \\
\hline (Continuous Production) $^{2}$ & $\begin{array}{c}-7396.56^{* * *} \\
(1729.96)\end{array}$ \\
\hline Constant & $\begin{array}{c}4466.87^{* * *} \\
(596.87)\end{array}$ \\
\hline Observations & 2159 \\
\hline Groups & 240 \\
\hline $\mathrm{R}^{2}$ & 0.04 \\
\hline
\end{tabular}

Notes: $*, * *, * * *$ indicate $10 \%, 5 \%$ and $1 \%$ statistical significance, respectively. Time period is 19902001.Standard errors clustered at the county-state level in parentheses. Year dummies are included but not shown. The average productivity, short tons per employee, is 9186 throughout the sample, so the increase in productivity due to sales to plants in restructured states is $11.4 \%$.

Table 8: Average productivity of continuing and discontinuing mines (short tons/employee 1991-1995).

\begin{tabular}{ccccc}
\hline \hline Year & Continuing (A) & Discontinuing $(\mathrm{B})$ & $t$-statistic & $\operatorname{Pr}(A-B>0)$ \\
\hline 1990 & 7366.82 & 6980.24 & 0.40 & 0.35 \\
1991 & 7293.20 & 7019.98 & 0.28 & 0.39 \\
1992 & 7748.92 & 7563.48 & 0.18 & 0.43 \\
1993 & 8646.62 & 7703.35 & 0.83 & 0.21 \\
1994 & 9606.38 & 8499.53 & 0.82 & 0.21 \\
1995 & 10169.09 & 8525.49 & 1.16 & 0.13 \\
\hline \hline
\end{tabular}


Table 9: Contract Renegotiations

\begin{tabular}{lc}
\hline \hline & \multicolumn{2}{c}{ Poisson } \\
\cline { 2 - 2 } & Time to Renegotiation \\
\hline Rigidity & $-0.19^{* * *}$ \\
& $(0.02)$ \\
Duration & $0.03^{* * *}$ \\
& $(0.01)$ \\
Post Restructuring & -0.03 \\
& $(0.05)$ \\
Mine-mouth Plant & $0.36^{*}$ \\
Constant & $(0.21)$ \\
& $1.96^{* * *}$ \\
\hline Observations & $(0.10)$ \\
Psuedo $R^{2}$ & 1,826 \\
\hline \hline
\end{tabular}

Notes: *, **, *** indicate $10 \%, 5 \%$ and $1 \%$ statistical significance, respectively. Robust standard errors in parentheses. Time period is 19902001. Vintage dummies included but not shown. 